تاريخ الإرسال (21-21-21)، تاريخ قبول النشر (10-71021)

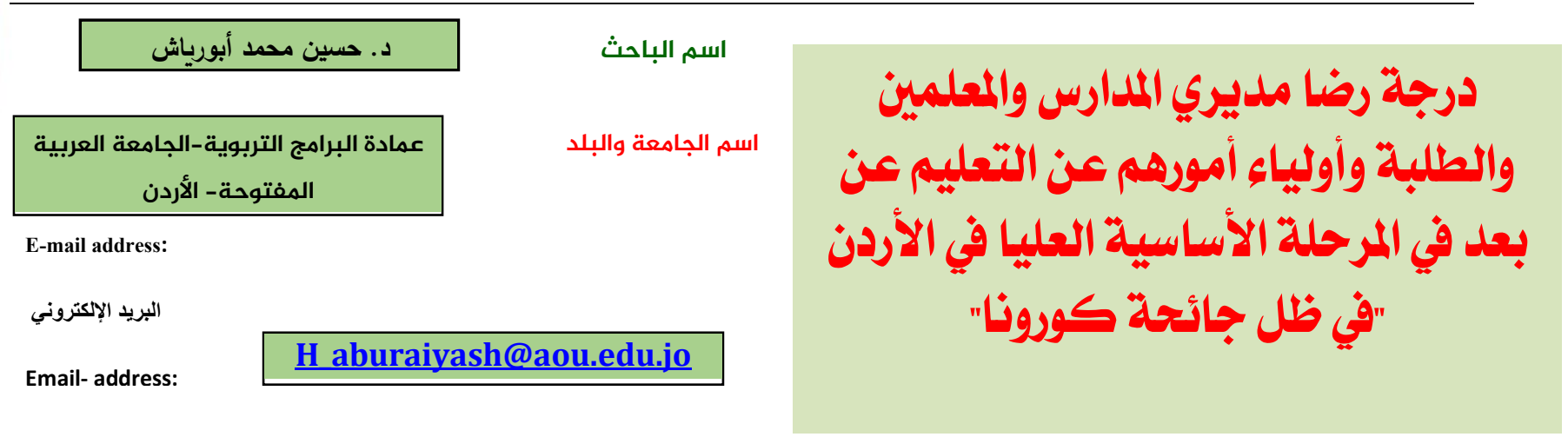

\title{
https://doi.org/10.33976/IUGJEPS.30.1/2022/10
}

الملخص:

هدفت هذه الدراسة التعرف إلى الكثف عن درجة رضا مديري المدارس والمعلمين والطلبة وأولياء أمورهم في المدارس الأساسية

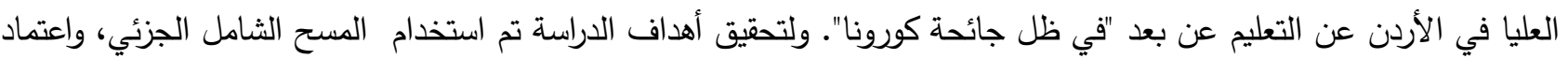

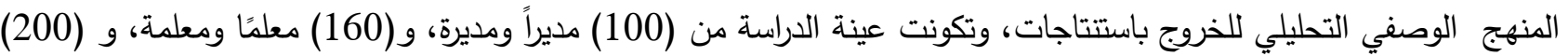

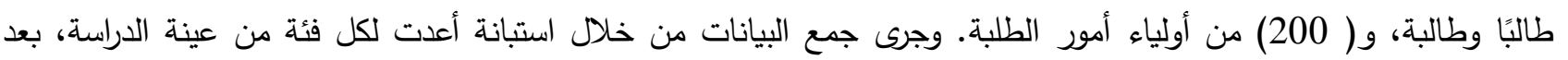
التأكد من الخصائص السيكومترية لكل أداة. وكثفت النتائج أن درجة الرضا عن التعليم عن بعد لدى مديري المدارس والمعلمين

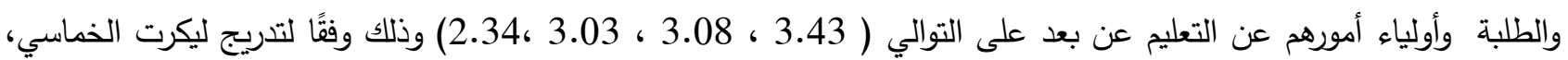
وجميعها جاءت بدرجة متوسطة. وخرجت الدراسة بمجموعة من التوصيات من بينها أن يكون التعليم عن بعد جزءاً من العملية

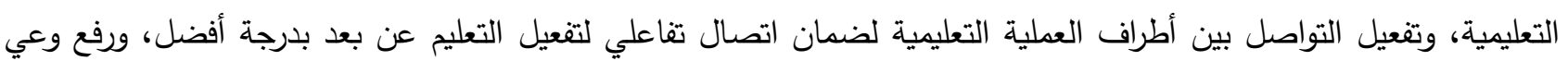
أولياء الأمور بماهية التعليم عن بعد.

كلمات مفتاحية:( درجة الرضا، التعليم عن بعد، الكورونا، المرحلة الأساسية العليا)

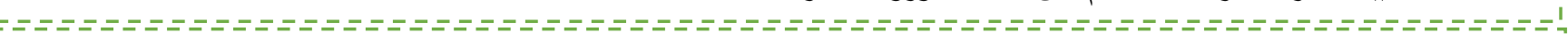

\section{درجة رضا مديري المدارس والمعلمين والطلبة وأولياء أمورهم عن التعليم عن بعد في المرحلة الأساسية العليا في الأردن "في ظل جائحة كورونا"}

\section{Abstract:}

This study aimed to investigate the degree of satisfaction of school principals, teachers, students and parents " in light of the Corona pandemic" with regard to distance learning in higher Pasic schools in Jordan. To achieve the goals of the study, the descriptive and analytical approach was adapted, and the study sample consisted (100) school principals, (160) male and female teachers, (200) male and female students and (200) parents. The data was collected through a questionnaire prepared for each category of the study sample, and the psychometric properties of each tool were conformed. The results revealed that the degree of satisfaction with distance education among school principals, teachers, students and their parents about distance education, respectively $(3.43,3.08,3.03$, and 2.34), according to Likert's quintile scale, and all of them came to a medium degree. The study came out with a set of recommendations, including that distance education be part of the educational process, and activate communication between the parties to the educational process to ensure interactive communication to activate distance education in a better degree, and raise parents' awareness of what distance education is.

"Keywords: (Satisfaction Degree, Distance Learning, Corona, Higher Pasic stage) 
شهد المجتمع العالمي بثكل عام، والمجتمع العربي بشكل خاص في ظل جائحة كورونا تغيرًا مُّسارعًا نحو التعلم الإكتروني، خاصـة في مجال توظيف التعليم عن بعد الذي أصبح حاجة ملحة للانتقال من التعليم التقليدي إلى التعليم باستخدام الوسائط الإلكترونية. فقد أصبح التعليم عن بعد ضرورة ملحة، وخصوصًا في وقت الأزمات، وانتشـار الأوبئة والفيروسات التي تتطلب التباعد الاجتماعي.

وفي المعركة ضد فيروس كورونـا المستجد (COVID-19) استبدلت الدول التعليم التقليدي عن قرب بالتعليم عن بعد كأداة دفاعية، على الرغم من تعرض العديد من الدول في السابق لكوارث طبيعية، وكوارث من صنع الإنسان، ولم يتم استخدام التعليم عن بعد كحل لتلك الأزمات بنفس الطريقة التي تم تطبيقها في أعقاب جائحة (CIVID-19). ويعد التعليم عن بعد أثناء الأزمات Crises Distance Education (CDE) عن بعد النموذجي بعدة طرق (Abdulrahman et al.,2020). أول اختلاف هو مفاجئته، حيث تم توظيف (CDE) في المدارس بدافع الحاجة غير المتوقعة، مع عدم وجود لوائح أو إعداد مسبق، حيث تـم الدفع بـالمعلمين والطلبة بـدون المعرفـة والمهارات اللازمـة، وتم الإسـراع بـه لإنقـاذ الفصـول الدراسية، وإعـادة

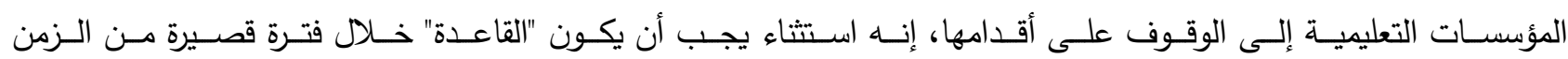
.(Rangiwai, 2020) والاختلاف الثاني هو التدويل، حيث تم تطبيق (CDE) كتدخل غير صيدلاني anon-pharmaceutical في جميع أنحاء العالم، مما أدى إلى تثكيل واقع عالمي، وتحويل التعليمات إلى مشهد عالمي، كمحاولة لإضفاء الطابع المؤسسي على التعليم عن بعد (Abdulrahman et al.,2020). والثالث جماهيرية التعليم عن بعد، فقد تمت المناقثات حول هذا الموضوع بسرعة، وأصبح مصلحة مشتركة عبر المجتمعات، حيث توضح( Google Trends) أن تكرار البحث عن عبارة" التعليم عن بعد" قد تضاعفت عشرات المرات في أعقاب جائحة كورونا (Muller et al.,2020, Google,2020). والرابع اعتبار (CDE) تدبيرًا صـارمًا في العديد من الدول، ومتطلبًا وطنيًا، حيث تم فرضـه دون تصويت، ولا بأي شكل من

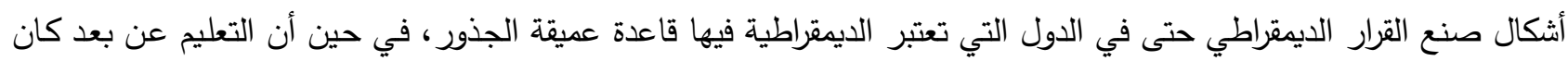

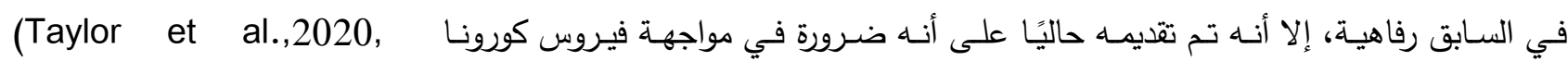
.Cornok,2020) قبل(COVID-19)، كان هناك بالفعل نموًا كبيرًا في تطبيق تكنولوجيا التعليم، سواءً كانت هذه التطبيقات لغوية أو دروس

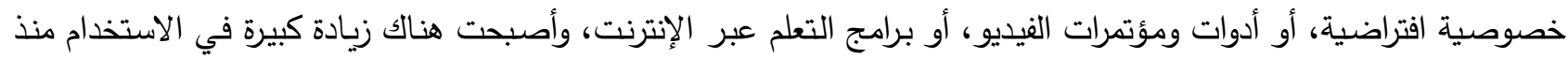

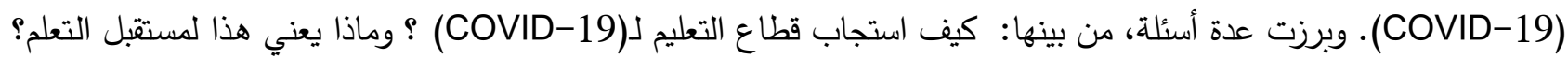
وماهي تحديات التعليم عن بعد؟ وهل التعليم عن بعد فعّال؟ وما نسبة عدد الطلبة الذين يتلقون التعليم عن بعد بوضوح؟ وهل

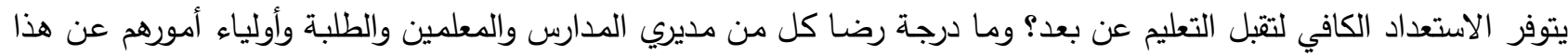

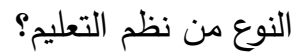
وتثير الدراسات أن هناك حاجة لتغيير الممارسات التعليمية الرسمية من الأساليب التقليدية إلى المناهج التعاونية التي تركز على الطالب، والموجهة ذاتيًا لإنشاء جيل قادر على التكيف مع منطلبات الرقمية (Khaddage et al.,2016)، وكما يشير 
تقرير هوريزون Horizon للتعلم من ريـاض الأطفال للصف الثاني عشر اهتمامًا أكبر بالتعلّم القائم على المشكلات، والتعلم

التعاوني والنشط، مع نمو التفاعل عن بعد، وكل ذلك يتم تسهيله بواسطة التكنولوجيا (Adams Backer et al.,2016). وعلى الرغم من وجود اتفاق قوي للربط بين التعلم الرسمي وغير الرسمي، لا تزال هناك العديد من التحديات لاستخدام

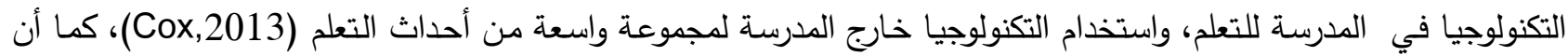
هناك العديد من القيود المتعلقة بعلم أصول التدريس، والسياسة التعليمية (Schuck et al.,2017)، إذ انه ليس من السهل تقييم نتائج التعلم عن بعد.

ويعد التطوير المهني للمعلمين طريقة لمواجهة العديد من التحديات، حيث يحتاج المعلمون إلى فهم الوسائل المساعدة في تسخير ممارسات التعلم غير الرسمية والمعرفة والمهارات التي يتم تطويرها عبر الممارسات اليومية لدعم تحقيق نتائج التعلم الرسمية، كما يحتاج الطلاب أيضًا إلى مزيد من الدعم من معلميهم لإنشاء المزيد من الثبكات بين التعلم داخل المدرسة وخارجها، وقد يكون من لن

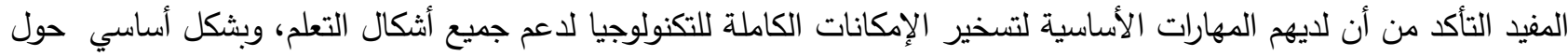

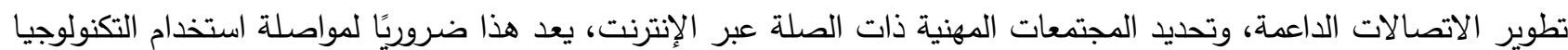

لاعم التعلّم مدى الحياة(Khaddage et al,2016). ويتقق العديد من العاملين في العملية التعليمية على أن التعليم عن بعد أصبح ضرورة لا غنى عنها، وسببًا مهمًا للنهوض بالعملية التعليمية، وتحقيق مخرجات التعلم التي يخطط لها، ودفع التطور السريع للمعرفة والتكنولوجيا لدى المعلمين، والبحث عن صن أفضل الوسائل والأساليب التي تمكن المتعلمين من التعلم، وتوفير بيئة تعليمية تفاعلية تتاسب احتياجات المتعلمين في القرن

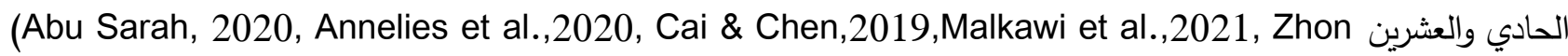
et al,2020)

كمـا أصبح دمـج التكنولوجيا في التدريس والتعلم مطلبًا حيويًا لتطوير الهياكل التعليمية استجابة للفرص التي توفرها الثورة

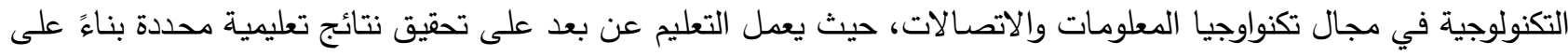
نتائج البحوث؛ من أجل تحقيق هذه الأهداف بأعلى درجة من الكفاءة (Zhou et al.,2020). غالبًا ما تكون الأحداث (العالمية الكبرى) نقطة انعطاف للابتكار السريع- ومن الأمثلة الواضحة على ذلى ذلك ظهور التجارة الإلكترونية بعد سارس SARS. بينما لا يزال يتعين على التربويين والخبراء معرفة ما إذا كان هذا سينطبق بنجاح على التعلم

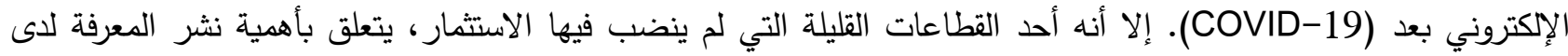

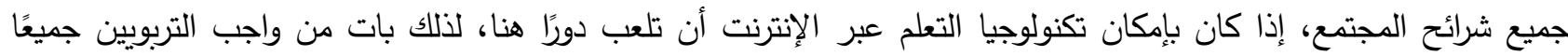
استكثاف إمكاناتها الكاملة. وقد ألقت جائحة كورونا بظلالها على المجتمعات العربية، والمجتمع الأردني بشكل خاص، مما أدى إلى تعاظم المسؤولية

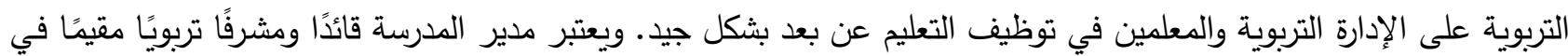

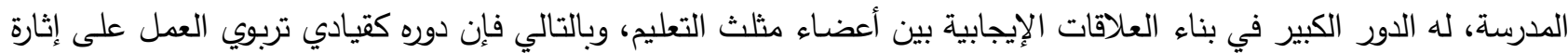

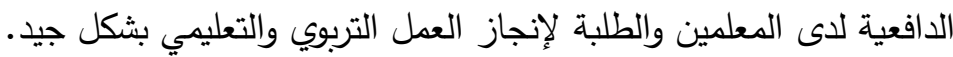
إن جائحة كورونا دفعت بالمؤسسات التعليمية للتحول إلى التعلم الإلكتروني(E-Learning) كبديل طال الحديث عنه والجدل حول ضرورة دمجه في العملية التعليمية؛ خاصـة بعد أن تأثرت العملية التعليمية بشكل مباشر بأتمتة الصناعة وتطور تكنولوجيا "الذكاء الصناعي "،و "إنترنت الأثياء(Internet of Things) "، وكذلك ثورة تكنولوجيا المعلومات التي اقتحمت معظم أشكال حياة الإنسان وأصبحت جزءا أصيلاً منه، حيث تشير الأدبيات أن التعلّم عن بعد موجود منذ أكثر من (100) عام، وتطوّر من التعلم بالمراسلة الذي بدأ في أوروبا، وظلت هذه الوسيلة الأساسية للتعلم عن بعد حتى منتصف القرن العشرين، عندما أصبح التعليم 
الإذاعي والتلفزيوني أكثر شيوعًا)، ومع تغير التكنولوجيا تغير تعريف التعلّم عن بعد، حيث أصبحت المحاضرات المسجلة بالفيديو معيارًا في الدورات الجامعية والمهنية، ثم تم استخدام الأشرطة الصسوتية، والدروس المرسلة عبر البريد في في الدورات التدريبية بالمراسلة لتدريس موضوعات مثل اللغة الأجنبية، ثم اتخذت الإنترنت والفيديو المضغوط التعلم عن بعد في اتجاهات جديدة، مما سمح بالتعلم عن بعد الذي نشهده في الوقت الحاضر (Hop Kentnor,2015 ). الدور الذي لعبه الفيروس في إخراج مشروع التعليم عن بعد من الأدراج إلى التطبيق العملي في كثير من مدارسنا وجامعاتتا،

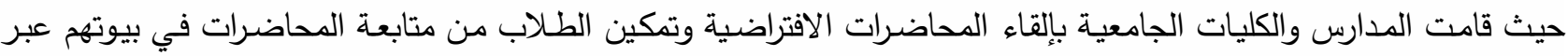
أجهزة الكمبيوتر، ولولا هذه الجائحة الوبائية لما قامت مدارسنا وجامعاتتا بممارسة التعليم عن بعد بهذا الثراء.

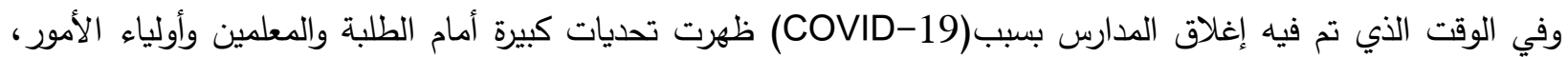
خاصة أولياء الأمور الذين لديهم أبناء في المدارس بين رياض الأطفال والصف الثاني عشر ، وهذه التحديات تحتاج إلى تضافر الجهود من مختلف الأطراف تخطيطًا وإعداداً وتتفيذاً ومتابعة وتقييمًا، وهذه تعتبر إثكالية في التطبيق المفاجئ للتعليم عن بُعد.

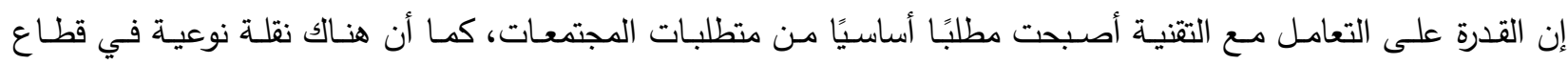
الاتصالات والتكنولوجيا وتطورها المتسارع. لذلك فإن النظام التعليمي يعتبر أحد مقومات بناء المجتمعات، وعليه فإن التعليم عن بعد يعتبر داعمًا لعملية التعليم التقليدية، وهو التعلم المستقبلي. فقد واجهت إدارات المدارس والمعلمين تحديات كبيرة في تطبيق هذا لهات

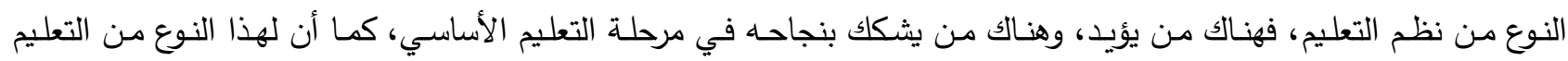

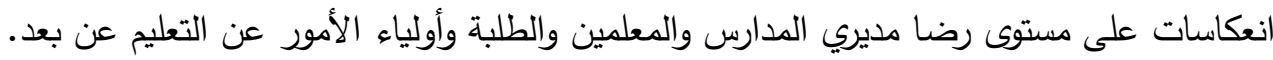

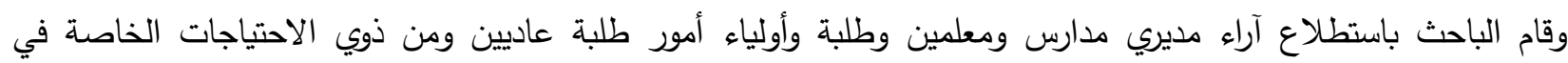
القطاعين العام والخاص، بلغ عددهم عشرة من كل فئة، للتعرف على قصصهم في تجربتهم مع التعليم عن بُعد. ومن خلال

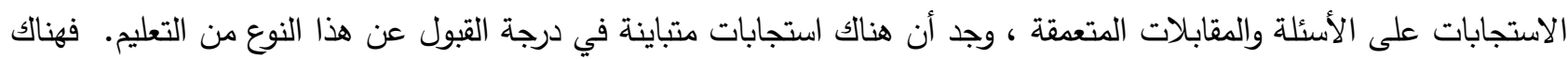

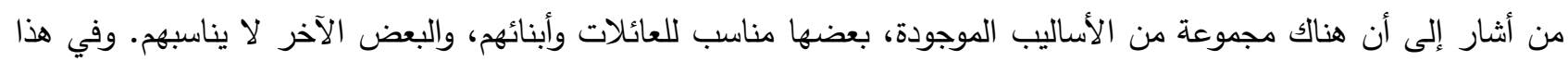
الصدد أشارت نتائج دراسة أبو شخيدم (2020)أن تقييم عينة دراستها لفاعلية التعليم الإلكتروني كان متوسطا، كما أشارت نتائج دراسة الجاسر (Aljaser,2019) إلى وجود فروق ذات دلالة لصالح المجموعة التجريبية في كل من اختبار ما بعد التحصيل في دئي اللغة الإنجليزية، كما أظهرت نتائج دراسة (Hodges et al.,2020) وجود اختلاف في تجارب التعلم عبر الإنترنت عن التعلم في حالات الطوارئ من حيث جودة التخطيط، والدورات المقدمة عبر الإنترنت استجابة لأزمة أو كارثة.

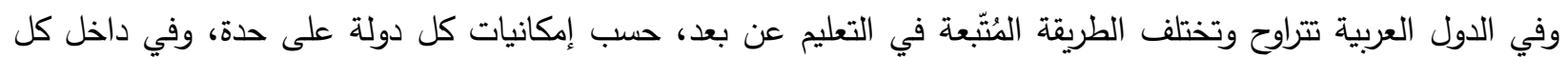
دولة، حيث فجوات رقمية قومية ووطنية، وجاهزية بنيتها التقنية التحتية، نظرًا لافتقار الكثير من هذه الدول للمستلزمات، والتجهيزات المتعلقة بالتعليم عن بعد، مع عدم توفر تجارب مسبقة لقياس مدى نجاحها في حال تطبيقها، كإجراء احترازي لمواجهة فيروس هذه كورونا. مشكلة الدراسة: تسبب تفثي فيروس (COVID-19) في إغلاق المدارس في جميع أنحاء العالم، مما أثر على (103) مليون طالب في جميع أنحاء الثرق الأوسط وشمال أفريقيا في منتصف شهر مارس(2020). وكان الأردن من أوائل الدول في المنطقة التي استجابت للأزمة من خلال فرض إغلاق وطني لجميع المؤسسات التعليمية، للحفاظ على التعلّم أثثاء الوباء. ولجأت وزارة التربية

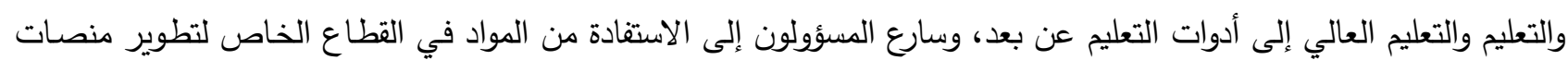
تعليمية تسمى "درسك Darsak"، إضافة إلى قناتين تلفزيونتين مخصصتين تقدمان دروسًا عبر الإنترنت، تغطي هذه الموارد المواد 
الأساسـية للـــهج الدراسـي، وهـي: اللغـة العربيـة، والإنجليزيـة، والرياضـيات، والعلـوم للصـفوف مـن الأول إلـى الثـاني عشـر

.(Mohammed,Maja \& Aishwarga,2020)

إضـافة لذلك، تم إعـادة توجيـه القنـاة الرياضـية التلفزيونيـة في الأردن لبث مواد تعليميـة مخصصـة للطـلاب الذين يستعدون لاختبارات الثانوية العامة(التوجيهي)، كما دعمت وزارة التربية والتعليم أعضاء هيئة التدريس من خلال طرح تلخحلات جديدة لتسهيل

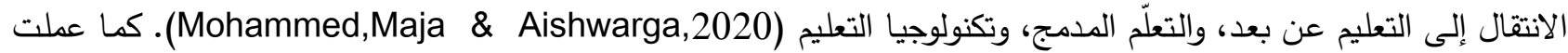
وزارة التربية والتعليم الأردنية، وفي ظل "جائحة كورونا" على تطبيق نظام التعليم عن بعد من خلال إطلاق عددٍ من المنصـات

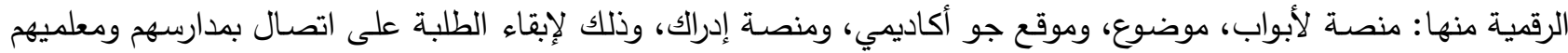
ومناهجه الدراسية، وأجواء العملية التعلمية التعليمية بثكل عام. أن اعتماد هذا التوجه بصورة مفاجئة دون استعداد مسبق، وتهيئة البيئة المناسبة قد يؤدي إلى نتائج عكسية، واتجاهات سلبية

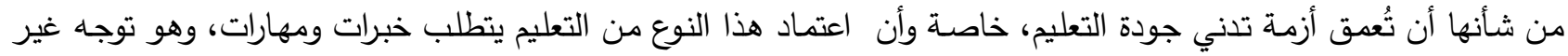
مكتمل-من وجهة نظر الباحث-في الأردن، بالنظر لمهارات المدرسين والطلبة في التعامل مع تقنية التعليم عن بعد، كما إن القفزة المفاجئة في تطبيق هذا النوع من نظم التعليم التي أحدثتها جائحة (COVID-19) تمثل تحديًا إضافيًا للمعلمين والطلبة وأولياء الأمور ، فقد لا يشعر الطلبة الذين كانوا يتلقون تعليمهم شخصيًا مع مدرس بدوام كامل بالراحة أثناء التتقل في التطبيقات والبرامج المستخدمة الآن لتلقي دروسهم، وإكمال مهامهم التعليمية. ولكن إزاء ما قامت بهه وزارة التربية والتعليم الأردنية لإكمال دورها الأساسي في التعايهي التعليم، إلا أنه برزت آراء متباينة حول مدى

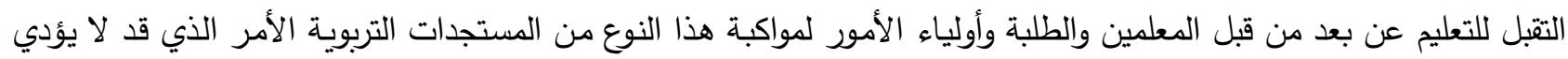
إلى النتائج المتوقعة، وذلك وفق الدراسة الاستطلاعية التي قام بها الباحث، الأمر الذي دعا إلى إجلى إجراء هذه الدراسة لاستقصـاء

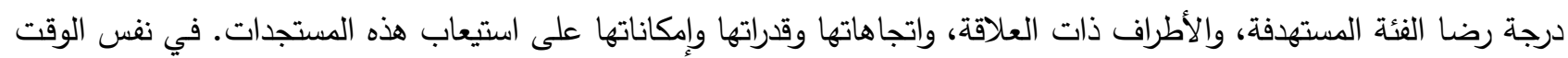

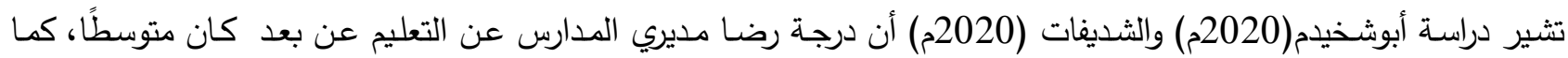
أثـارت نتائج دراسـة باسيليان كفافدز (Basilain,Kvavadze,2020) في جورجيا أن تجربـة الانتقال من التعليم التقليدي إلى على التعليم عبر الإنترنت كان ناجحًا، كما أظهرت نتائج دراسة شايم واوفر (Chayim \& Offir,2019) إلى وجود نتائج إيجابية للتعليم عن بعد، وكذلك دراسة سيمتز وفوجت (Smitns \& Voogt,2017) أن عوامل الرضا عن التعليم عن بعد أن إحدى مجموعات

الطلبة قد سجلت درجات رضا عالية، وحصلت المجموعة الثانية على تقييمات منذفضة لرضا الطلاب عن التعليم هن بعد.

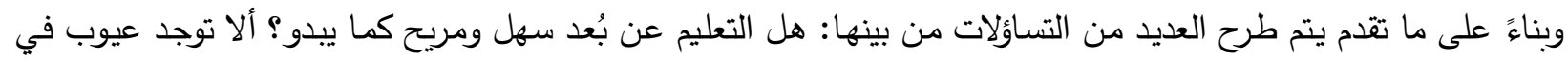

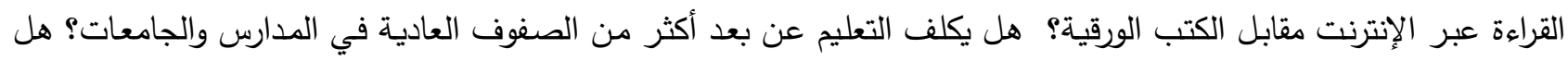
سيحصل الطلاب على نفس جودة التعليم عن بُعد كما يحصلون في صفوفهم العادية؟ وهل التعليم عن بعد يُعزز الكفاءة الذاتية عelf-efficacy

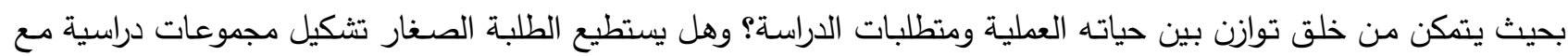
زملاء آخرين ، وتبادل الخبرات لإحداث التعلم المطلوب؟ وهل يستطيع هؤلاء الطلبة التعرّف إلى نقاط ضعنههم، وتحديد الأفراد أو

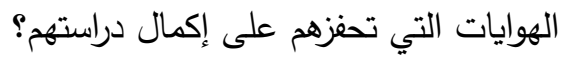
وبناءً على ما تقدم ، حاولت الدراسة الإجابة عن عالهُ السؤال الرئيس الآتي: ما درجة رضا مديري المدارس والمعلمين والطلبة وأولياء أمورهم نحو التعليم عن بعد في المدارئ الإس الأساسية الأسية العليا في الأردن "في ظل جائحة كورونا" من وجهة نظرهم ؟ ماته ويتغرع عن هذا السؤال الأسئلة الفرعية الأربعة الآتية: 
1- ما درجة رضا مديري الددارس نحو التعليم عن بعد في المدارس الأساسية العليا في الأردن "في ظل جائحة كورونا" من وجة نظرهم ؟

2- ما درجة رضا المعلمين نحو التعليم عن بعد في المدارس الأساسية العليا في الأردن "في ظل جائحة كورونا من وجهة نظرهم؟

3- ما درجة رضا الطلبة نحو التعليم عن بعد"في في الددارس الأساسية العليا في الأردن ظل جائحة كورونا من وجهة نظرهم؟

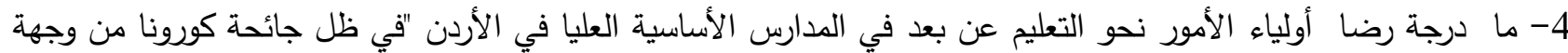

تسعى الدراسة الحالية إلى تحقيق الأهداف الآتية:

1- التعرف إلى درجة رضا مديري المدارس نحو التعليم عن بعد في المدارس الأساسية العليا في الأردن "في ظل جائحة كورونا" من وجهة نظرهم.

2- التعرف إلى درجة رضا المعلمين نحو التعليم عن بع في المدارس الأساسية العليا في الأردن د"في ظل جائحة كورونا" من وجهة نظرهم. 3- التعرّف إلى درجة رضا الطلبة نحو التعليم عن بعد في المدارس الأساسية العليا في الأردن "في ظل جائحة كورونا" من وجهة نظرهم. 4- التعرف إلى درجة رضا أولياء الأمور نحو التعليم عن بعد في المدارس الأساسية العليا في الأردن "في ظل جائحة كورونا" من وجهة نظرهم. أهمية الدراسة:

الأهمية النظرية:

تتبع أهمية الدراسة من أهمية التعليم عن بعد بوصفه تقنية تربوية حديثة في العملية التعلّمية التعليمية في المنطقة العربية بشكل عام، والأردن بثكل خاص، حيث يساهم في حل الكثير من المشكلات المستجدة في طور الأزمات، خاصة " جائحة كورونا"، والعمل بنظام التعليم الجزئي للطلبة، وما يثكل ذلك عبئًا على الطلبة والمعلمين وأولياء الأمور •

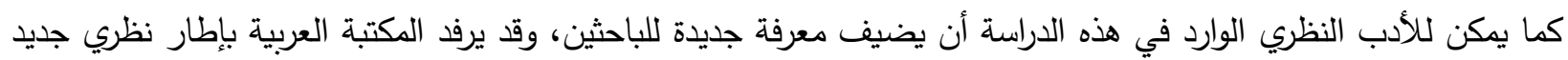
حول التعليم عن بعد في ظل الجوائح والأزمات، وقد تفيد الدراسات السابقة المهتمين بالتعليم عن بعد ونتائج تطبيقه عمليًا. الاهمية العملية: يمكن لنتائج هذه الدراسة أن تتعكس بشكل إيجابي عن وجود حالة رضا متوسطة عن التعليم عن بعد لدى مديري المدارس،

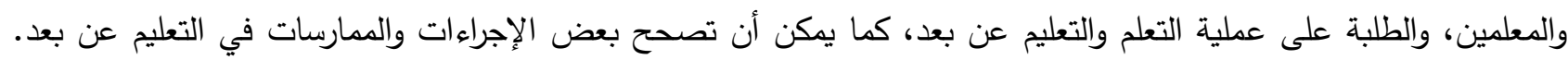
وبالتالي تفيد نتائج الدراسة القائمين على العملية التعليمية بمختلف مستوياتها في تحسين أداء نظم التعلم عن بعد التي يتم تطبيقها، وتطوير الكوادر البشرية، والإمكانات المادية، والاتجاهات المستقبلية للتوجه نحو التعلم عن بعد كبديل للتعليم التقليدي أو مساندًا له. كما يمكن الاستفادة من أدوات الدراسة في قياس مدى فاعلية التعلم عن بعد في المدارس، وأيضًا تستمد الدراسة أهميتها كونها معاصرةً لظاهرة واقعية، وهي انتشار (COVID-19)، وعملية الاستفادة من نتائجها فيظواهر مشابهة كالحروب والعات والأزمات. تعريف المصطلحات: درجة الرضا: هي مدى انسجام مديري المدارس والمعلمين والطلبة وأولياء الأمور مع خدمات التعليم عن بعد التي تقدمها وزارة

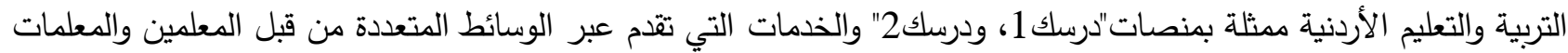


في هذه المدارس. وتقاس درجة الرضا من خلال الدرجة التي يحصل عليها كل فرد من عينة الدراسة على الأداة المعدة لهذا الغرض.

مدير المدرسة : تثير المادة (18) من قانون التربية والتعليم وتعديلاته في الأردن هو الثخص المعين رسميًا في وزارة التربية والتعليم ليكون مسؤولاً عن تسيير عمليات المدرسة المختلفة باتجاه تحقيق أهدافها التربوية.، ويشترط أن يكون حاصلًا على مؤهل تربوي لا تقل مدة الدراسة فيه عن سنة دراسية واحدة بعد الدرجة الجامعية الأولى (البكالوريوس)، وذا خبرة في التعليم في الوزارة لا

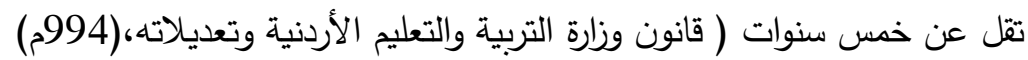

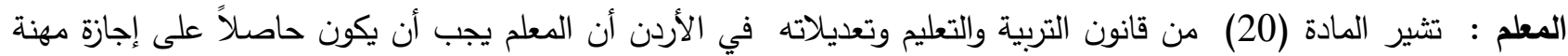
التعليم، حيث تمنح هذه الرخصة للمعلم في مرحلة التعليم الأساسي للشخص الحاصل على الدرجة الجامعية الأولى، ويشمل ذلك لكئل

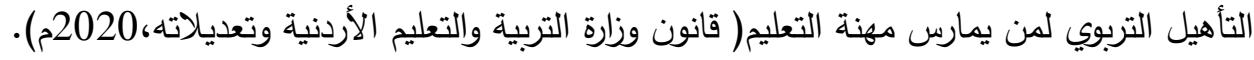
التعلم عن بعد والتعليم عن بعدئ يمارس معندي فرق كبير بينهما؛ لأن كليهما يؤديان الغرض فيما يتعلق بأن هناك مسافة بين المعلم والمتعلم. حيث تتم عملية التدريس والتعلّم التي تتضمن نقل واكتساب المعارف والمهارات عبر وسائط متعددة، والتي تُستخدم نظراً للبُعدين بين المعلم والمتعلم (Tony

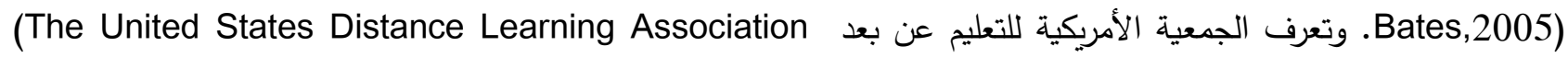
(التعليم عن بعد بأنه" توصيل للمواد التعليمية أو التدريبية عبر وسيط إليكتروني يثمل الأقمار الصناعية وأشرطة

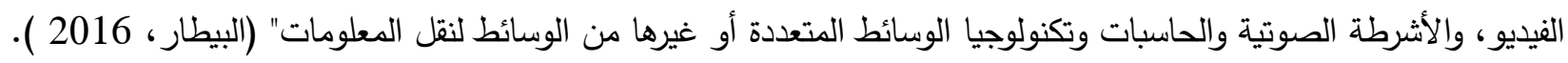

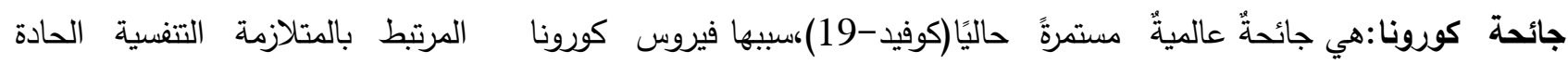

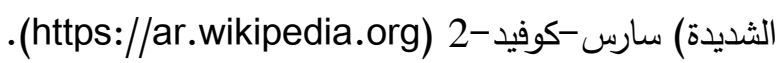
المرحلة الأساسية العليا: حسب نظام وزارة التربية والتعليم في الأردن، تُعرّف بأنها إحدى مراحل التعليم العام في المدارس التي

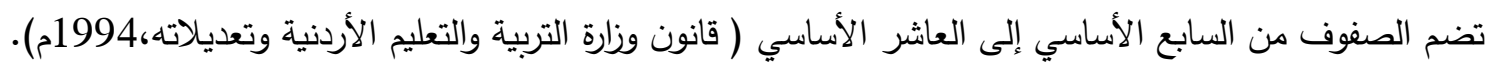
حدود الدراسة: تتحدد الدراسة الحالية بما يلي: -حدود بشرية: مديري ومديرات المدارس والمعلمين والمعلمات والطلبة في الطلبة في المدارس الأساسية الحكومية في الأردن، وأولياء أمور الطلبة. -حدود زمانية: أُجريت هذه الدراسية في الفصل الدراسي الأول من العام الدراسي 2020/2021. -حدود موضوعية تتحدد بأدوات الدراسة (استبانات درجة الرضا عن التعلم عن بعد لكل من : المديرين، المعلمبن، الطلبة، أولياء الأمور) • وما توفر لها من خصائص سيكومترية. - العينة المتيسرة/ الحصصية.

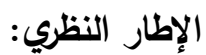

يعد "التعليم عن بعد" من أحد اهم الأدوات التعليمية الحديثة، حيث يتم نقل الحصص الصفية والمعلومات المنهجية عبر وسائل التكنولوجيا من المؤسسة التعليمية الى الطلاب. وذلك في ظل الظروف الراهنة لانتشار فيروس كورونا والذي اجتاح العالم كله، تم

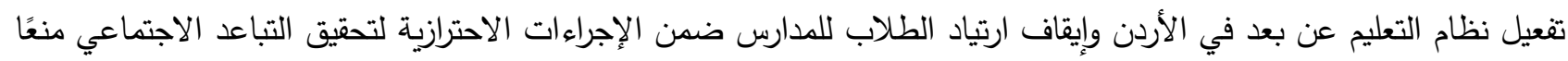
لانتشار الفيروس، واستطاعت الحكومة الأردنية تفعيل بديل يحاكي الأزمة الحالية من خلال قنوات تلفازية، ومنصات الإدئ الكترونية أشهرها منصة درسك التعليمية التي تبث الدروس المتلفزة عبر قناة الأردن الرياضية. 
وأثارت نتائج استطلاع قام به معهد غرب اسيا وشمال افريقيا (WANA Institute) عن استطلاع الطلاب للدراسة عن بعد نسبة 22.2\% من العينة أجابوا بأنه لايوجد استجابة نهائيًا من قبل الطلاب، مما يعني أن هناك نوعًا من عدم التقبل للدروس

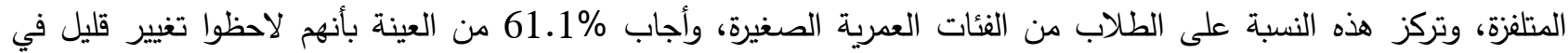
الاستجابة نحو الأفضل، و 16.7\% من الإجابات كانت تشير إلى أن هناك استجابة سريعة وتحسن في أداء الطلاب، كما أشار 46.7\% من العينة المستهدفة أن لا حاجة لاستمرار نظام التعلم عن بُعد بعد انتهاء الإجراءات الاحترازية لجائحة كورونا، ويُفضلون العودة لنظام التعليم الصفي في المدارس، وأثنار 31.1\% من العينة المستهدفة عن عدم تأكدهم من نجاعة استمرارية أو عدم استمرارية نظام التعليم عن بعد، بينما فضل 21.1\% من العينة المستهدفة عن استمرار نظام التعليم عن بعد حتى بعد انتهاء الحجر الصحي (http://wanainstitute.org/ar).

وتثير الدراسات أن الأطفال يستخدمون حواسهم على نطاق واسع للتعلم، لذا فإن جعل التعلم ممتعًا وفعالاً من خلال استخدام التكنولوجيا أمر بالغ الأهمية، وفقًا لمرينال موهيت Mrinal Mohit على مدار فترة زمنية، لاحظت أن التكامل الذكي للألعاب

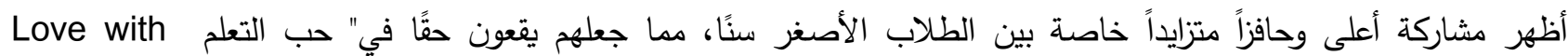

.Learning ويشير تقرير المركز الأوروبي للتدريب التتموي والمهني CEDFOP أن (كوفيد -19)عطّل تعليم وتدريب جيل كامل من متعلمي التعليم والتدريب المهني (VET) Vocational and Educational Training (أولئك المعرضون بالفير الفعل للخطر - من الخلفيات الاجتماعية والاقتصادية المحرومة والمهاجرين والأقليات العرقية والمتعلمين ذوي الإعاقة والمتعلمين من ذوي الاحتياجات

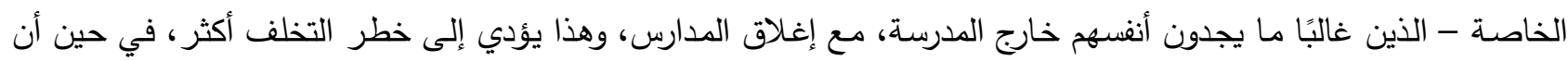

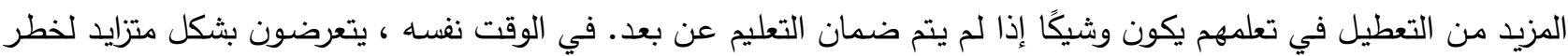

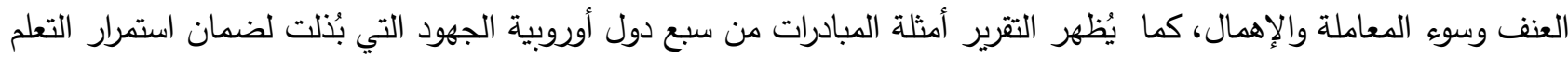

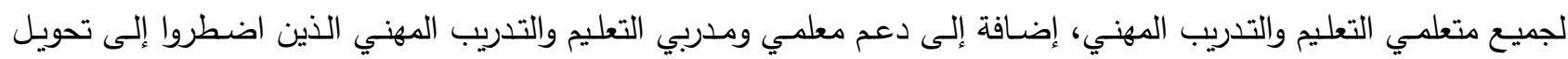
الفصول الدراسية وأماكن العمل إلى بيئات تعليمية رقمية بين عشية وضحاها (CEDFOP,2021). ويُعد التعليم عن بُعد وسيلة فعّالة وهادفة ومهمة للحصول على المعرفة والاكتثافات وقت حدوثها، وذلك لمواجهة متغيرات

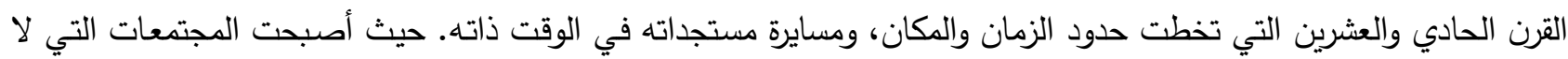
توظف التعليم عن بعد مجتمعات غير متطورة، ويصعب عليها التعايش في هذا العصر، ومن هذا المنطلق اهتم العالم بأنظمته التربوية المختلفة عن التعليم عن بعد. وفي الأردن عملت وزارة التربية والتعليم على استخدام التعليم المدمج-مزيج من تقديم الخدمات التعليمية (عن بعد) ووجهًا لوجه في الفصل كوسيلة لخلق بيئة تعليمية فعًالة، وذلك لتجنب الإصابة بعدوى (COVID-19). الاراسات السابقة: قام الباحث بالرجوع لبعض الدراسات السابقة التي تتاولت متغيرات الدراسة، وتم ترتيبها من الأحدث إلى الأقدم.

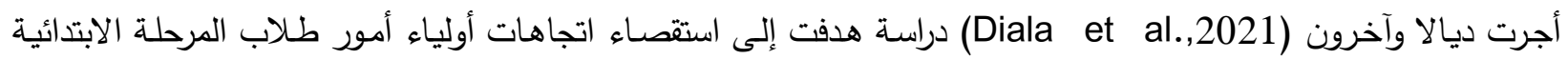
والثانوية في الأردن تجاه عملية التعليم عن بعد التي تم تتفيذها في ظل جائحة كورونا. ولتحقيق أهداف الدراسة استخدم الباحثون أسلوب المسح الوصفي لجمع البيانات وتحليلها وتفسير النتائج، وذلك بعد تطوير استبانة تم التأكد من موثوقيتها، تم توزيعها على تلى

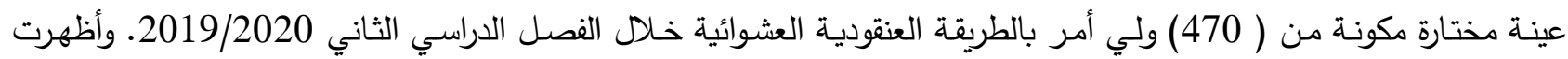
النتائج أن أولياء أمور طلاب المرحلة الايتدائية والثانوية كانوا راضين إلى حد ما عن عملية التعلم عن بعد، إضافة لذلك، كثفت 
النتائج عن فروق ذات دلالـة إحصـائية في اتجاهات الوالدين تعزى إلى متغيرات الصف (5-7)، وإلى جنس المعلم لصـالح المعلمات، ونوع المدرسة لصالح المدارس الخاصة. وفي دراسة أجراها (Shu Cui et al.,2021) هدفت إلى استقصاء تجارب واتجاهات طلاب المدارس الابتدائية وأولياء

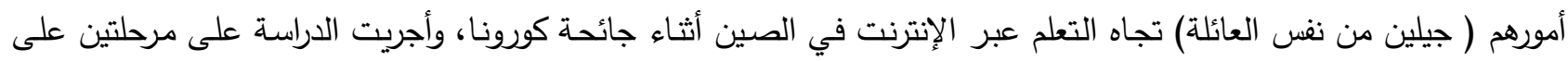
نفس العينة، وتم توزيع استبانة مكونة من (16) فقرة وزعت على (867) زوجًا من الآباء وأطفالهم، وتكونت الاستبانة من أسئلة

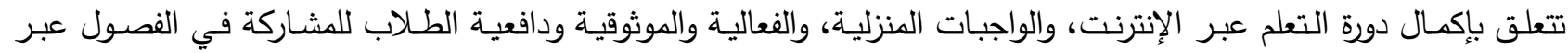

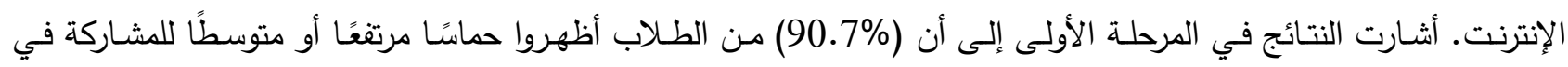

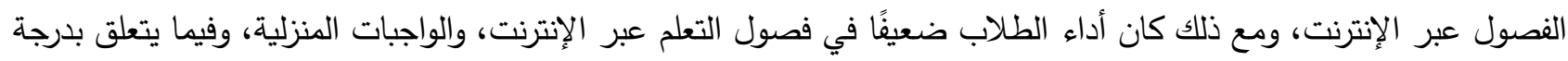
رضا أولياء الأمور والطلاب كان (7.35 و 7.25) على التوالي من نظام مكوّن من عشرة نقاط. وأشارت النتائج في المرحلة الثانية إلى انخفاض التقييمات الايجابية لأولياء الأمور للتعلم عبر الإنترنت، بما في ذلك تلك التهلى التعلة بفعالية الدورات وموثوقيتها، علاوة على ذلك انخفض الرضا العام لأولياء الأمور والطلاب عن التعليم عبر الإنترنت، وكانت درجة الرضا عنداء عند أولياء الأمور والطلاب على التوالي( 7.21 و 7.23) من نظام مكوّن من عشرة نقاط، ومع ذلك فإن الاختلاف العام بين المرحلتين لم يكن ذاء الإداء

دلالة إحصائية. في دراسة أجراها (Giorgi Basilai, DavidKvavadze,2020) هدفت إلى دراسة تجربة الانتقال من التعليم الوجاهي إلى الى التى

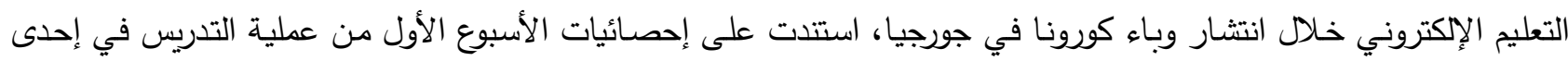

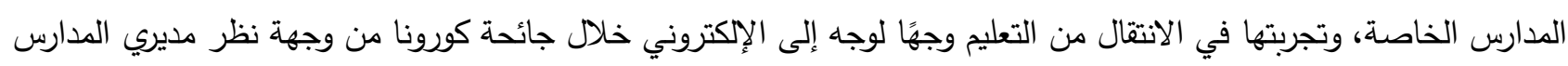
والمعلمين، حيث قامت بمناقثة نتائج التعلم عبر الإنترنت باستخدام منصتي (Gsuite \& EduPage) في العملية التعليمية.

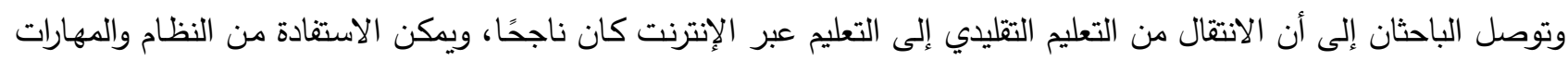

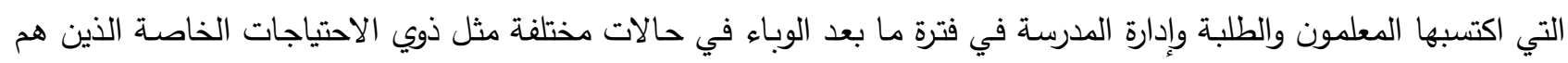

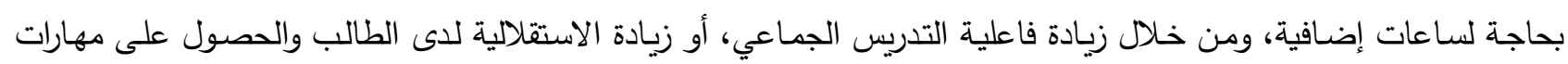
جديدة. وأجرى (Itish Sharm \& Deepti Kira,2020) دراسة هدفت التعرف على درجة رضا أولياء الأمور عن الفصول الدراسية

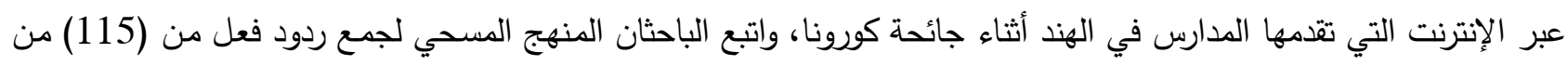

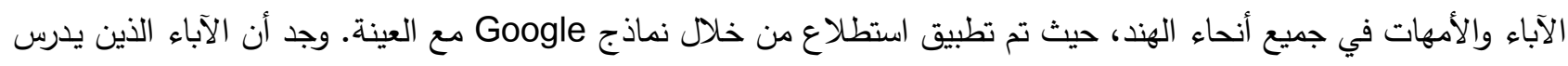

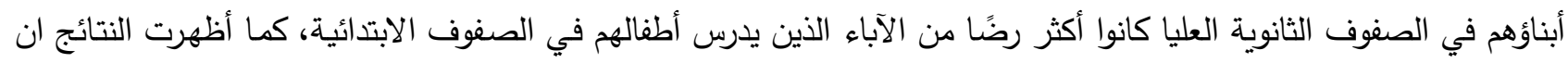
هناك ثلاثة عوامل: فعالية بيئة التعلم، معالجة المعلومات، والفعالية الفنية للمدرسة، لها تأثير ايجابي على الرضـا العابـ العام لأولياء الأمور تجاه الفصول عبر الأنترنت. وفي دراسة أجراها المقدادي(2020م) هدفت إلى الكشف عن تصورات طلبة المرحلة الثانوية في الددارس الحكومية في الأردن

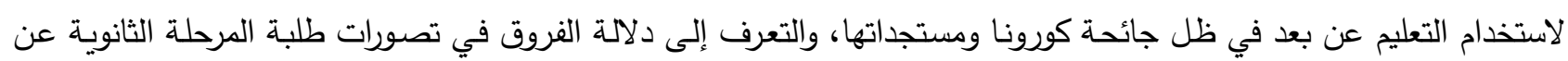

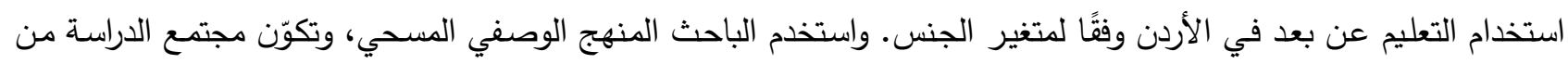
طلبة المرحلة الثانويـة في المدارس الحكومية في لواء قصبة اربد، وتكونت عينة الدراسة من (167) طالبًا وطالبة، تم اختيارهم بالطريقة العشوائية البسيطة، طبق استبانة للكثف عن تصورات العينة لاستخدام التعليم عن بعد. وخلصت الدراسة إلى أن هناك

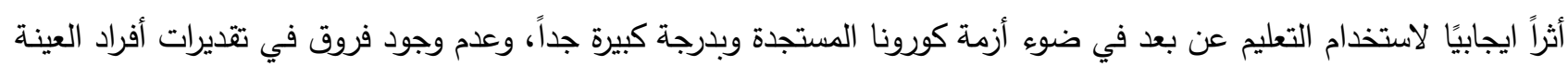

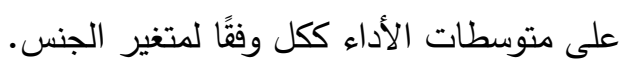


Ministry of Higher Education and Scientific ) وقامت وزارة التعليم العالي والبحث العلمي الأردنيـة (Research,2020 بتطبيق استبانة لاستطلاع أراء الطلبة للوقوف على درجـة رضـاهم عن فاعلية التعليم عند بعد،حيث بلغ مستوى الرضـا \%54.4 وعن الوسـائل والتتنيـات بنسبة رضـا عنها بلغت 55.93\%والمحتوى الإككترونسي بنسبة رضـا بلغت 52.56\% وفاعلية التدريس بنسبة رضـا بلغت 56.83\%، والتتييم بنسبة رضـا بلغت 50.63\% أمـا نسبة الرضـا عن فاعلية التدريس الإكتروني لطلبة الماجستير فقد بلغت \% 70.54 و 53.06 لطلبة برنامج البكالوريوس، فيما بلغت 50.14 لطلبة الدبلوم المتوسط(http://www.mohe.gov.jo).

وفي دراسة الثديفات (2020م) التي هدفت التعرف إلى واقع توظيف التعليم عن بعد بسبب جائحة الكورونا في مدارس قصبة المفرق من وجهة نظر مديري المدارس فيها، حيث بلخ حجم مجتمع الدراسة (163) مديرًا ومديرة، وتكونت العينة من (145)

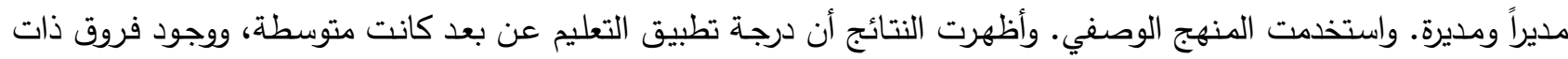
دلالة في تقديرات أفراد العينة لواقع توظيف التعليم عن بعد تبعًا لمتغير الجنس ولصالح الإناث، وعدم وجود فروق ذات دلالة تبعًا لمتغير المرحلة الدراسية. وفي دراسة شبه تجريبية قام بها الجاسر (Aljaser,2019) هدفت التعرف على فاعلية بيئة التعلم الإكتروني في تطوير

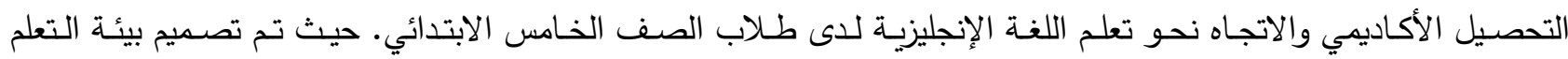

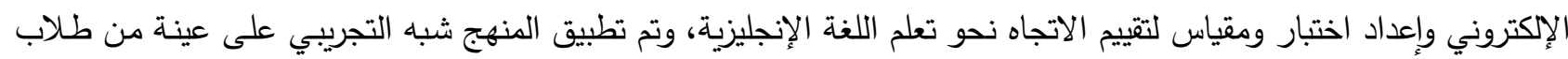
الصف الخامس، مقسمة إلى مجموعة ضابطة تدرس من خلال الطريقة التقليدية، ومجموعة تجريبية تدرس من خلال بيئة التعلم

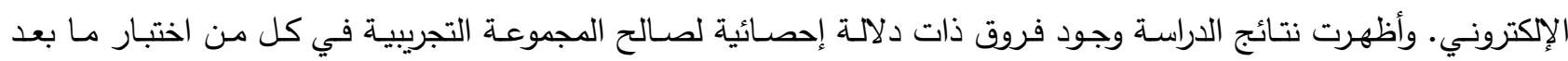
التحصيل ومقياس الاتجاه نحو تعلم اللغة الإنجليزية. وفي دراسة أجراها حمادنة والثواهين (2019م) هدفت التعرف إلى اتجاهات معلمي الرياضيات نحو التعليم الإلكتروني في

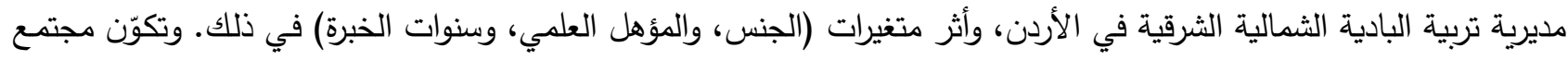

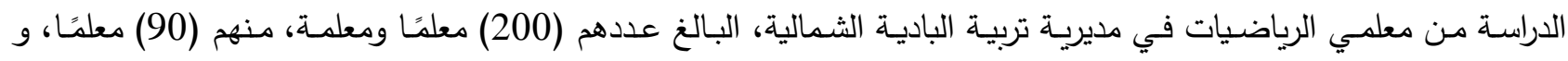
(110)معلمات، وتكونت العينة من (100) معلم ومعلمة تم اختيارهم بالطريقة العشوائية البسيطة، طبق عليهم مقياس الاتجاهات

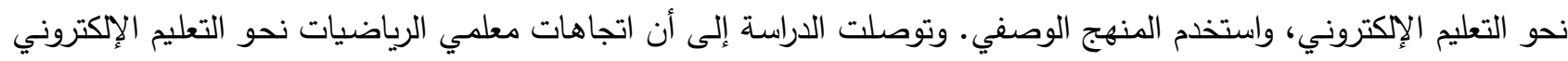

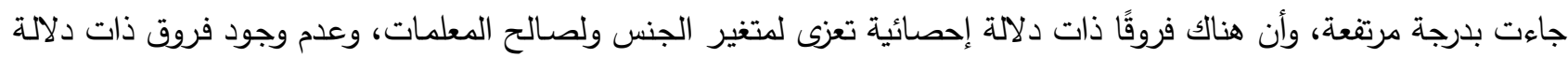
تعزى لمتغير المؤهل العلمي، ووجود فروق ذات دلالة تعزى لمتغير سنوات الخبرة، ولصالح الخبرة أقل من خمس سنوات.

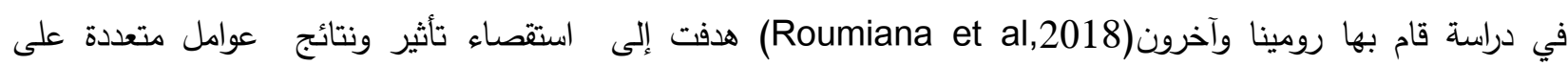
اتجاهات الطلاب نحو التعلم عبر الإنترنت والتعليم عن بعد. تكونت عينة الدراسة من (590) طالبًا في جامعة صوفيا (بلغاريا) من طلبة السنتين الثالثة والرابعة، والذين يدرسون عن طريق التعلم عبر الإنترنت، والتعليم عن بعد. وتكونت أداة الدراسة من التصني

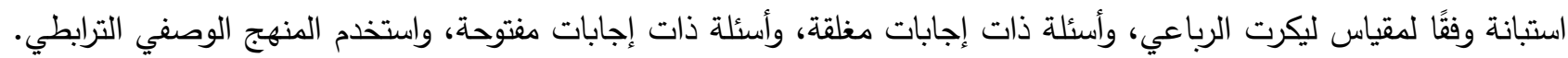
وتوصلت إلى استتاجات من بينها أن الدراسة مفيدة للمجتمع الأكاديمي، ولكل من يهتم بتخطيط وتطوير وتتفيذ استراتيجيات التعلم عبر الإنترنت والتعليم عن بعد. في دراسة قام بها سمه كالسكان وآخرون(Semih Caliskan et al ,2017) الغرض منها تحديد مستويات رضا الطلبة الجامعيين الذين يدرسون في جامعة خاصة عن الدورات المقدمة من خلال التعليم عن بعد، واستخدم الباحثون منهجية البحث النوعي، وتكونت العينة من (107) طلاب يدرسون في كليات مختلفة، طبقت عليهم استبانة: الرضا عن التعلم عن بعد"، وتم جمع البيانات من خلال استطلاع عبر الإنترنت، وأظهرت النتائج رضا الطلبة عن الدورات التي تقدم بتثنية التعليم عن بعد. 
في دراسة قام بها عبيد وآخرون(Obaid et al.,2017) هدفت إلى استقصساء اتجاهات طلبة الجامعة تجاه التعليم عبر الإنترنت في منطقة بيثاور ، وركزت الدراسة بثكلٍ أساسي على استكثاف العلاقة بين مواقف طلبة الجامعة تجاه نموذج قبول التكنولوجيا مع إشارة خاصـة إلى التعلم عبر الإنترنت. وتكوّن مجتمع الدراسة من حميع طلبة جامعة بيشاور ، تم تطبيق استبانة

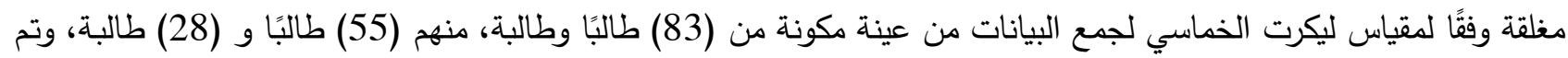

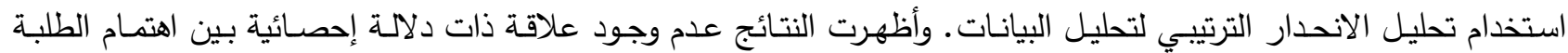
بالكمبيوتر وفائدته لهم وسهولة استخدام التعلم عبر الإنترنت. وأجرى العشيري (2016م) دراسـة هدفت إلى معرفة اتجاهات طلبة الجامعة العربية المفتوحة في مملكة البحرين نحو نظام التعليم المفتوح، ولتحقيق أهداف الدراسة استعان الباحث بالمنهج الوصفي التحليلي، ومقياس لقياس اتجاهات الطلبة نحو التعليم المفتوح. وتكونت العينة من (452) طالبًا وطالبة من تخصصـات (إدارة الأعمال، وتقنية المعلومات، واللغة الإنجليزيـة وآدابها)، وتوصلت الدراسة لعدة نتائج أهمها: وجود اتجاه بدرجة متوسطة لدى طلبة الجامعة نحو التعليم المفتوح، وعدم وجود تأثير لمتغيري الجنس والبرنامج التعليمي الذي يدرس فيه الطالب على اتجاهات الطلبة نحو نظام التعليم المفتوح، واعتقاد طلبة الجامعة بأن

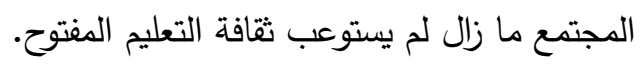
في دراسة أجراها الشريف (2016م) هدفت التعرف على اتجاهات طلبة جامعة شقراء نحو التعليم الإلكتروني، ولتحقيق أهداف الدراسة استخدم الباحث المنهج الوصفي التحليلي، ومقياس لقياس الاتجاهات نحو التعليم الإلكتروني مكوّن من(28) فقرة. وتكوّن

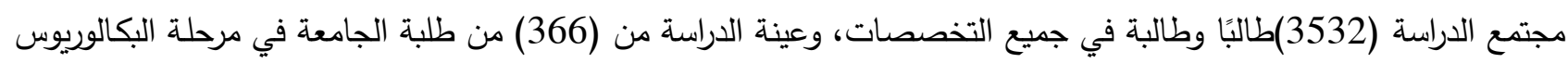

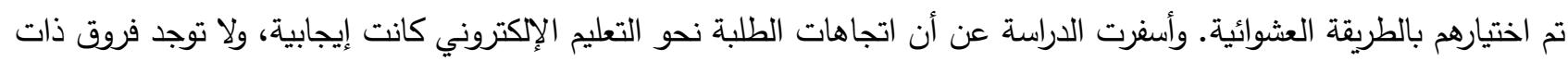

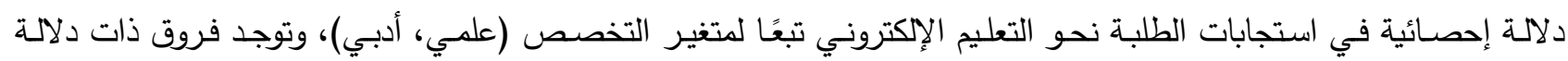

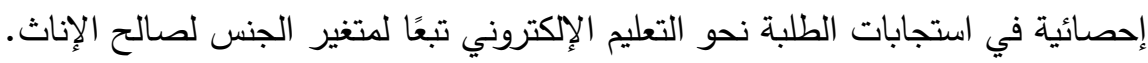
وفي دراسـة قام بها الزبون (2016م) هدفت إلى الكثف عن درجة توافر متطلبات التعلم الإلكتروني في تدريس التربية

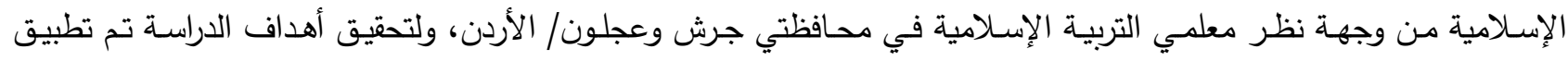

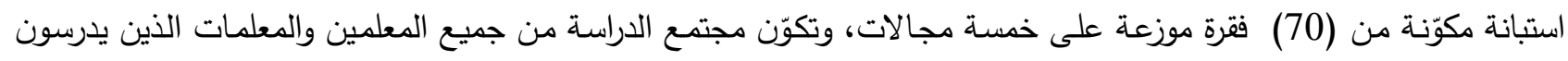
التربية الإسلامية في محافظتي جرش وعجلون البالغ عددهم (220) معلمّا ومعلمة، وتم استخدام المنهج المسحي المدرسي بطريقة

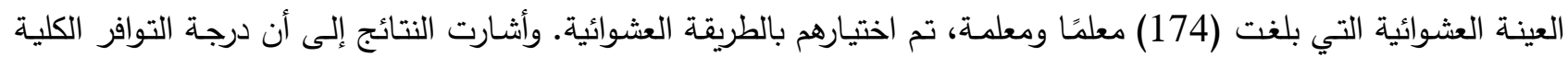
لمتطلبات التعلم الإلكتروني في التربية الإسلامية كانت متوسطة، حيث أن متطلبات تطبيق التعليم الإلكتروني المتعلقة بمعلم التربية الإسلامية في المرتبة الأولى، تلتها في المرتبة الثانية متطلبات التطبيق المتعلقة بالطالب، وفي المرتبة الثالثة المتعلقة بالمنهاج، وفي المرتبة الرابعة المتعلقة بالأمور التنظيمية والفنية، وفي المرتبة الأخيرة المتعلقة بالبيئة التعليمية. وفي دراسة قام بها البيطار (2016م) هدفت التعرّف على فاعلية استخدام التعلم عن بعد في تتمية التحصيل الدراسي والاتجاه نحو التعليم عن بعد في مقرر تكنولوجيا التعليم لدى طلاب الدبلوم العامة نظام العام الواحد شعبة التعليم الصناعي بكلية التربية بجامعة أسيوط. وتكونت أدوات الدراسة من دليل المعلم للتعليم عن بعد لمقرر تكنولوجيا التعليم، واختبار تحصيلي، ومقياس الاتجاه نحو التعليم عن بعد، واستخدم المنهج الوصفي في إعداد الإطار النظري، وأدوات ومواد الدراسة، وتحليل النتائج وتقسيرها.تكوّن

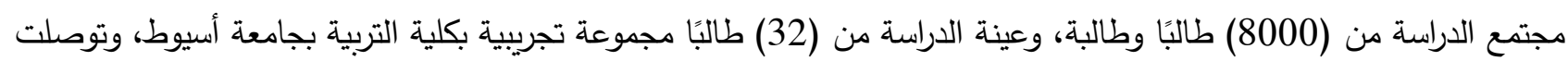
نتائج الدراسة إلى فاعلية استخدام التعليم عن بعد في تتمية التحصيل الدراسي والاتجاه نحو التعليم عن بعد. في دراسة قام بها (S.K.Ingec,2015) هدفت إلى تحديد اتجاهات الطلبة نحو التعلم الإلكتروني لدى طالبات الثانوية الفنية والمهنية للبنات ودراستها في ضوه بعض المتغيرات. وتم استخدام طرق المسح الفردية والارتباطية، وتكونت العينة من (119) 
طالبة بالمرحلة الثانوية المهنية. وجمعت البيانات من خلال مسح ورقي يتكوّن من جزأين، في الجزء الأول من الاستطلاع هناك

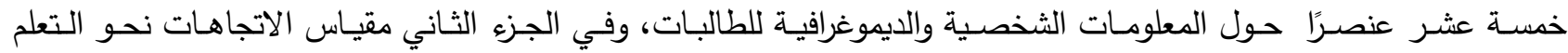
الإلكتروني، وأظهرت النتائج أنه لا توجد فروق دالة إحصـائيًا بين اتجاهات الطالبات من المدارس الفنيـة والمهنية نحو التعليم الإلكتروني فيما يتعلق بالجنس والخبرة. كما أجرى عوض وحلس(2015م) دراسة هدفت التعرّف إلى الاتجاه نحو تكنولوجيا التعليم عن بعد وعلاقته ببعض المتغيرات للى طلبة الدراسات العليا في كلية التربية بالجامعات الفلسطينية. وتكونت عينة الدراسة من (91) طالبًا وطالبة يدرسون ببرامج

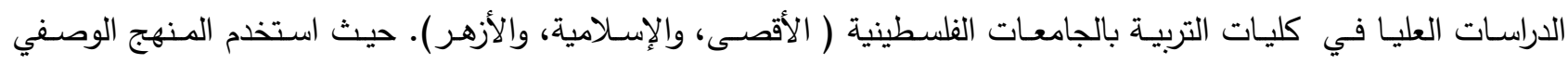

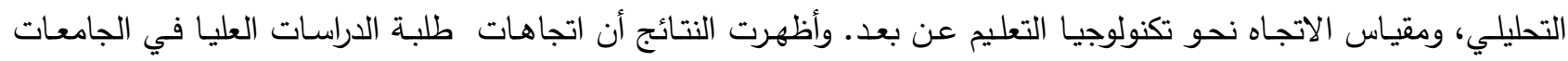
الفلسطينية نحو تكنولوجيا التعليم عن بعد كانت بدرجة مرتفعة وايجابية. كما أظهرت نتائج الدراسة عدم وجود فروق دالة إحصائيًا نحو التعليم عن بعد تبعًا لمتغيرات الجنس والمستوى التعليمي والتقدير العام، ووجود فروق دالة إحصـائيًا تبعًا لمتغير الجامعة فردة

باستعراض الدراسات السابقة وجد الباحث العديد من أوجه الاختلاف بين الدراسة الحالية والدراسات السابقة، حيث تباينت الدراسات في أهدافها، وعيناتها ونتائجها. فمعظم الدراسات كانت عيناتها من طلبة الجامعة، وتتاولت من ضمن متغيراتياتهاتهاتها الاتجاه نجو التعليم الإكتروني. فقد تتاولت دراسة الزبون(2016م) التعليم الإكتروني من وجهة نظر المعلمين، ودراسة الجاسر (2019) فاعلية بيئة التعلم الإكتروني والاتجاه نحوه لدى طلبة الصف الخامس الابتدائي، في حين تتاولت دراسة (A.K.Ingec,2015)

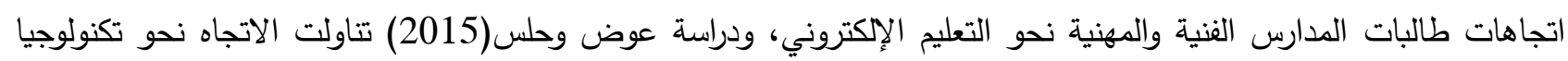
التعلم لدى طلبة الدراسات العليا. كما تعددت المناهج البحثية المستخدمة في الدراسات السابقة، فهناك المنهج الوصفي كما في ودراتي

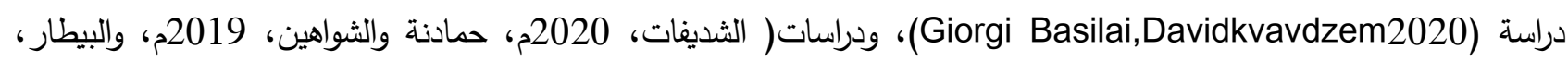
2016م)، والمنهج الوصفي التحليلي كما في دراسات (العشيري،2016م، والثريف،2016م)، والمنهج الوصفي الارتباطي كما في ودراني

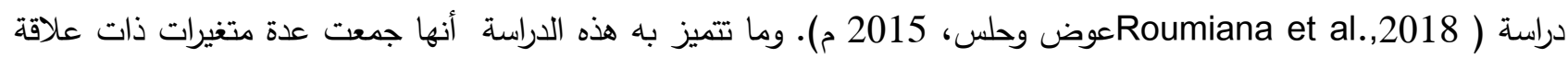
بالتعليم لم تجمع بينها الدراسات السابقة، خاصة في ظل جائحة كورونا. الطريقة والإجراءات:

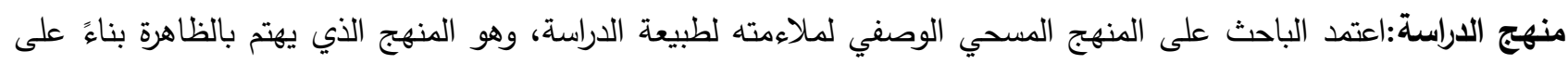

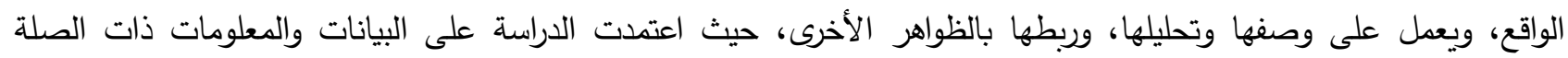
بالموضوع، والتي تم جمعها عن طريق الاستبانات. مجتمع الاراسة: تكوّن مجتمع الدراسة من مديري ومديرات ومعلمي ومعلمات المدارس الأساسية العليا الحكومية والطلبة في هذه

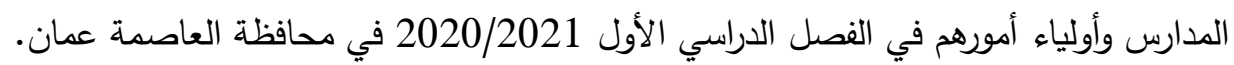
أفراد الدراسة: بلغ عدد أفراد الدراسة (660) فرداً وفق ما تمكن الباحث من الوصول إليهم. والجدول (1) يُبين توزيع أفراد الدراسة.

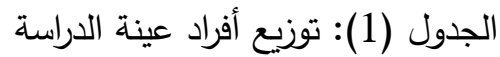

\begin{tabular}{|c|c|c|c|c|}
\hline المجموع & ولي أمر & طالب/طالبة & معلم/معلمة & مدير \\
\hline 660 & 200 & 200 & 160 & 100 \\
\hline
\end{tabular}


قام الباحث بإعداد أربع استبانات للتعرّف على درجة رضا مديري المدارس والمعلمين والطلبة وأولياء "أمورهم من وجهة نظرهم في التعلم عن بعد في الددارس الأساسية العليا في الأردن في ظل "جائحة كورونا". وذلك بعد الاطلاع على الأدبيات والدراسات

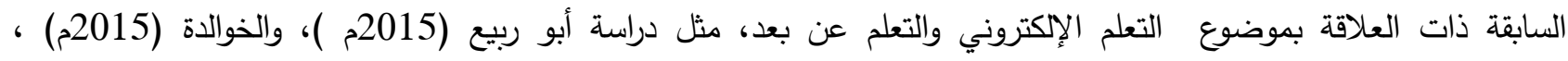

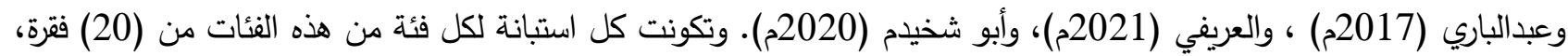

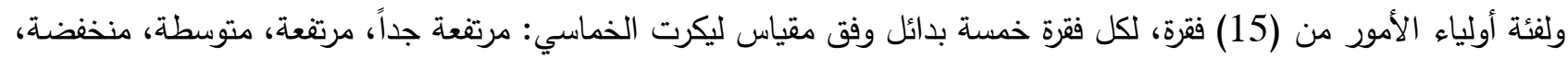
منخفضة جداً. وأعطيت هذه البدائل الدرجات الآتية على الترتيب (5 ، 4 ، 4 ، 3 ، 2 ، 1 1). وبالتالي تتراوح الدرجات لكل أداة بين (20-100) درجة لفئات مديري الددارس والمعلمين والطلبة، ومن (15-75 درجة) لفئة أولياء الأمور . وتم تصنيف درجة الرضا عن توظيف التعليم عن بعد لاى عينة الدراسة إلى ثلاثة مستويات ( منخفضة، متوسطة، مرتفعة) حسب متوسطات إجابات العينة لكل فقرة على النحو التالي: طول الفئة= (5-3/1)= 1.33، وبذل وبلك يكون حدود المستويات الثلاثة كما هو موضح في الجدول (2). جدول (2) التقدير الذي اتبعه الباحث في الحكم على مدى رضا مديري المدارس والمعلمين والطلبة وأولياء الأمور عن التعليم عن

\begin{tabular}{|c|c|c|}
\hline درجة مرتفعة & درجة متوسطة & درجة منخفضة \\
\hline $5.00-3.68$ & $3.67-2.34$ & $2.33-1$ \\
\hline
\end{tabular}

الخصائص السيكومترية لأدوات الدراسة:

تم تحكيم أدوات الدراسة من قبل متخصصين في علم النفس والتربية والقياس والتقويم وعلم الاجتماع من عدة جامعات، وعدد من

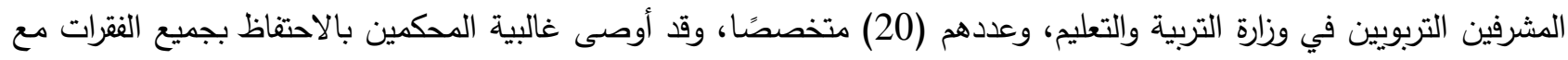

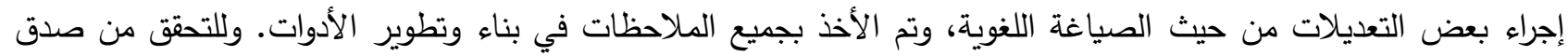
البناء، تم تطبيق الأدوات بصورتها النهائية على(10) من مديري المدارس الأساسية، وعلى(10) من المعلمين والمعلمات، و (20)

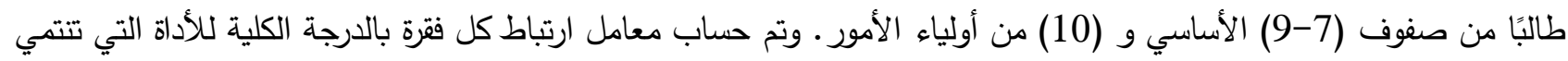
لها، وذلك باستخدام معامل الارتباط بيرسون. وأشارت النتائج إلى أن معاملات الارتباط للفقرات مع الأدوات التي تلتمي إليات اليها كانت مقبولة، إذ تراوحت بين ( 0.82- 0.89). وتم التحقق من دلالات ثبات كل أداة بطريقة الاتساق الداخلي، وبلغ معامل الثبات لمقياس الرضا عند مديري المدارس (0.70)، وعند المعلمين (0.73)، وعند الطلبة(0.82)، وعند أولياء الأمور (0.79)، وهي قيم مقبولة لأغراض الدراسة. نتائج الاراسة ومناقثتها:

للإجابة عن أسئلة الدراسة، تم إيجاد المتوسطات الحسابية والانحرافات المعيارية لإجابات أفراد عينة الدراسة. السؤال الأول: ما درجة رضا مديري المدارس نحو التعليم عن بعد في المدارس الأساسية العليا في الأردن"في ظل جائحة كورونا" من وجهة نظرهم؟ للإجابة عن هذا السؤال تم استخراج المتوسط الحسابي والانحراف المعياري والدرجة والوزن النسبي لكل فقرة، وكانت النتائج كما في الجدول(3). 
جدول(3): المتوسط الحسابي والانحراف المعياريودرجة الرضا والوزن النسبي لأداء مديري المدارس على مقياس الرضا عن التعليم عن بُعد

\begin{tabular}{|c|c|c|c|c|c|}
\hline 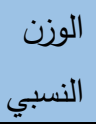 & 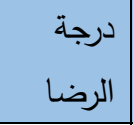 & 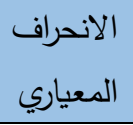 & الحستوسط & الفقرة & ? \\
\hline 12 & متوسطة & 0.45 & 2.75 & وفر المعلمون المادة العلمية للمتعلمين في صورة ملفات إليكترونية عبر التعليم & 1 \\
\hline 14 & متوسطة & 0.48 & 2.76 & التعلم المخطط لهات التعليم عن بعد التي وفرتها وزارة التربية والتعليم تكفي لتحقيق نتاجات & 2 \\
\hline 19 & منخفضة & 0.45 & 2.12 & 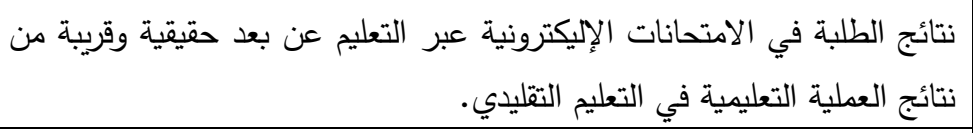 & 3 \\
\hline 20 & منخفضة & 0.35 & 2.09 & المناسبة المعلمون المعرفة الكافية في تصميم وتطوير الامتحانات الإليكترونية & 4 \\
\hline 17 & متوسطة & 0.59 & 2.47 & يدرب المعلمون الطلبة على المهارات الحياتية اللازمة عبر التعليم عن بعد. & 5 \\
\hline 4 & متوسطة & 0.48 & 3.36 & يراعي المعلمون أنماط التعلم المختلفة للطلبة عبر التعليم عن بعد. & 6 \\
\hline 5 & متوسطة & 0.67 & 3.34 & ساهم التعليم عن بعد من تكوين تغذية راجعة موضوعية عن أداء المعلمين. & 7 \\
\hline 3 & متوسطة & 0.84 & 3.553 & يمتخدمها المعلمون في التعليم. & 8 \\
\hline 7 & متوسطة & 0.76 & 3.09 & يشارك المعلمون الحوار بشكل جماعي أو فردي مع الطلبة عبر التعليم عن بعد. & 9 \\
\hline 6 & متوسطة & 0.79 & 3.29 & نفذ المعلمون المادة المعرفية الخاصة بالمنهاج الدراسي عبر التعليم عن بعد. & 10 \\
\hline 12 & متوسطة & 0.55 & 2.75 & التقليدية عبر التعلمون على إدماج الطلبة في أنشطة فعّالة تختلف عن أساليب التعليم & 11 \\
\hline 18 & متوسطة & 1.14 & 2.41 & يرسل ويستقبل المعلمون مقاطع الفيديو والمقاطع الصوتية إلى الطلبة عبر التعليم & 12 \\
\hline 15 & متوسطة & 1.08 & 2.67 & نظمت عدة اجتماعات مع المعلمين في مدرستي عبر تقنية التواصل عن بعد. & 13 \\
\hline 1 & 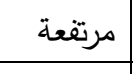 & 0.23 & 3.94 & عملت على إصدار تعليمات صريحة للمعلمين على تطبيق التعليم عن بعد. & 14 \\
\hline 15 & متوسطة & 0.72 & 2.67 & كنت أتواصل مع أولياء الأمور من خلال البوابة الإليكترونية للمدرسة. & 15 \\
\hline 10 & متوسطة & 0.87 & 2.83 & كنت أتواصل مع الطلبة من خلال البوابة الإليكترونية للمدرسة. & 16 \\
\hline 8 & متوسطة & 0.24 & 3.06 & ساعدت المعلمين في مدرستي التعرف على الأساليب المناسبة لممارسة التعليم & 17 \\
\hline 11 & متوسطة & 1.37 & 2.77 & ساعدت المعلمين على استثمار الوقت عند ممارسة التعليم عن بعد. & 18 \\
\hline 9 & متوسطة & 1.20 & 2.93 & عملت على نشر ثقافة التعليم عن بعد للطلبة وأولياء الأمور عبر البوابة & 19 \\
\hline \multirow[t]{2}{*}{1} & مرتفعة & 0.23 & 3.94 & عملت على تحفيز المعلمين لتطبيق التعليم عن بعد. & 20 \\
\hline & متوسطة & 0.66 & 3.43 & المقياس ككل & \\
\hline
\end{tabular}

يبين الجدول (3) أن المتوسطات الحسابية تراوحت ما بين (2.09 - 3.94)، حيث جاءت الفقرتين (14 و 19) واللتين تتصان على " عملت على إصدار تعليمات صريحة للمعلمين على تطبيق التعليم عن بعد" و" عملت على تحفيز المعلين لتطبيق التعليم 
عن بعد" في المرتبة الأولى، بمتوسط حسابي (3.94) وانحراف معياري (0.23)، بينما جاءت الفقرة رقم (8) والتي تتص على " تمكنت من خلال التعليم عن بعد من التعرف على طرائق ومهارات التدريس التي يستخدمها المعلمون في التعليم" في المرتبة الثالثة بمتوسط حسابي(3.55) وانحراف معياري(0.84) في المرتبة الثالثة، وجاءت الفقرتين (6، 7) في المرتبتين الرابعة والخامسة على لى

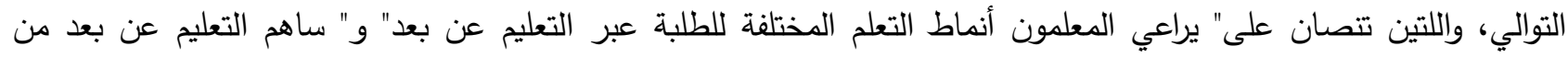

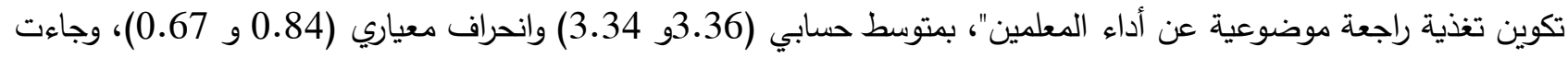
الفترتين (10،9) في المرتبتين (6،7) بمتوسط حسابي (2.12 و 2.09) وبانحراف معياري (0.45 و

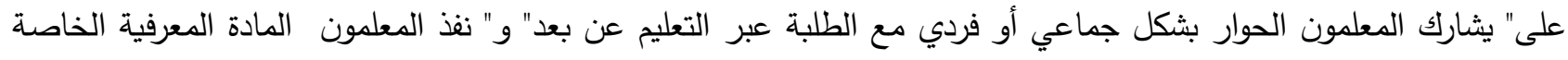

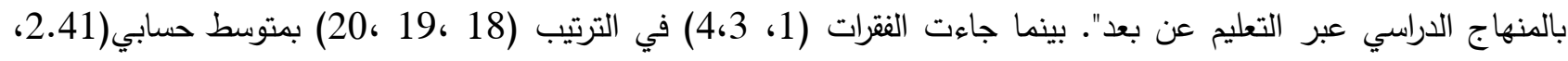

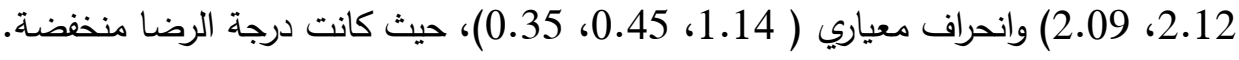

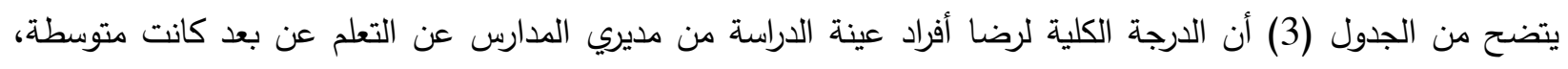

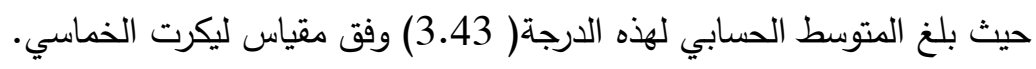
السؤال الثاني:ما درجة رضا المعلمين نحو التعليم عن بعد في المدارس الأساسية العليا في الأردن "في ظل جائحة كورونا" من لئن وجهة نظرهم؟ للإجابة عن هذا السؤال تم استخراج المتوسط الحسابي والاتحراف المعياري ودرجة الرضا والوزن النسبي لكل فقرة، وكانت النتائج كما في الجدول(4) جدول(4):المتوسط الحسابي والانحراف المعياري ودرجة الرضا والوزن النسبي لأداء معلمي المدارس على مقياس الرضا عن التعليم عن بُعد

\begin{tabular}{|c|c|c|c|c|c|}
\hline 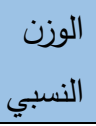 & 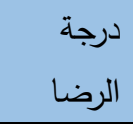 & 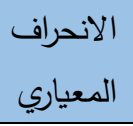 & الحسابي & الفقرة & r \\
\hline 11 & متوسطة & 0.70 & 3.00 & ساهم التعليم عن بعد في توضيح المادة العلمية للمتعلمين. & 1 \\
\hline 4 & متوسطة & 0.43 & 3.25 & ساهم التعليم عن بعد في تحقيق نتاجات التعلم الـخطط لها لدى المتعلمين. & 2 \\
\hline 11 & متوسطة & 0.71 & 3.00 & تمكن الطلاب من خلال التعليم عن بعد من إنجاز المهمات الدراسية المطلوبة & 3 \\
\hline 16 & متوسطة & 0.43 & 2.75 & حقق التعليم عن بعد الاتصال التعليمي المطلوب بيم المتعلمين بعضهم ببعض. & 4 \\
\hline 4 & متوسطة & 0.43 & 3.25 & مكن التعليم عن بعد من تحقيق التفاعل بين المعلم والمتعلمين. & 5 \\
\hline 20 & منخفضة & 0.71 & 2.00 & ساعد التعليم عن بعد في زيادة الدافعية للتعلم لدى المتعلمين. & 6 \\
\hline 2 & منخفضة & 0.71 & 2.00 & مكن التعليم عن بعد من تقدير أهمية توظيف التكنولوجيا من قبل المعلم في & 7 \\
\hline 4 & متوسطة & 0.43 & 3.25 & ساعد التعليم عن بعد المتعلمين على توضيح المعلومات والمفاهيم من خلال & 8 \\
\hline 1 & 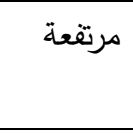 & 0.83 & 3.75 & أسهمت المنصات التعليمية التي وفرتها وزارة التربية والتعليم في تحفيز المعلمين & 9 \\
\hline 2 & متوسطة & 0.50 & 3.50 & أسهح التعليم عن بعد في زيادة نشاط وحيوية المتعلمين للتعلم. & 10 \\
\hline 4 & متوسطة & 0.43 & 3.25 & حفز التعليم عن بعد المتعلمين على ممارسة مهارات التعلم الذاتي. & 11 \\
\hline 2 & متوسطة & 0.50 & 3.50 & ساعد التعليم عن بعد على تتويع أساليب وطرائق التدريس. & 12 \\
\hline
\end{tabular}




\begin{tabular}{|c|c|c|c|c|c|}
\hline 4 & متوسطة & 0.43 & 3.25 & ساعد التعليم عن بعد في تقييم الطلبة تقييمًا موضوعيًا. & 13 \\
\hline 4 & متوسطة & 0.43 & 3.25 & زاد التعليم عن بعد من دافعية المعلم لممارسة مهنة التدريس. & 14 \\
\hline 11 & متوسطة & 0.71 & 3.00 & التعليم عن بعد أضاف عبئاً كبيراً على المعلم. & 15 \\
\hline 11 & متوسطة & 0.71 & 3.00 & وجدت صعوبة في تطبيق التعليم عن بعد لضعف الخبرة التقنية لدي. & 16 \\
\hline 4 & متوسطة & 0.43 & 3.25 & أشعر بعدم الرضا عن دور التعليم عن بعد في تعليم المرحلة الأساسية. & 17 \\
\hline 16 & متوسطة & 0.43 & 2.75 & التعليم عن بعد يراعي الفروق الفردية بين المتعلمين. & 18 \\
\hline 16 & متوسطة & 0.43 & 2.75 & عملت على تزويد الطلبة بالتغذية الراجعة عن أداءاتهم من خلال التعليم عن بعد. & 19 \\
\hline 11 & متوسطة & 0.71 & 3.00 & الفيديو). المنهج الدراسي للطلبة باستخدام الوسائط المتعددة( الصورة، الصوت، & 20 \\
\hline & متوسطة & 0.70 & 3.08 & 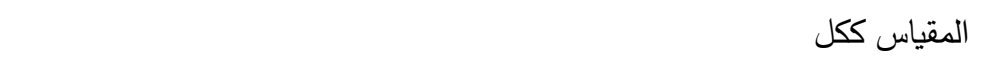 & \\
\hline
\end{tabular}

يبين الجدول (4) أن المتوسطات الحسابية تراوحت ما بين (2 - 3.75)، حيث جاءت الفقرة رقم (9) والتي تتص على " أسهمت المنصات التعليمية التي وفرتها وزارة التربية والتعليم في تحفيز المعلمين على توظيف التكنولوجيا" في المرتبة الأولى، بمتوسط التيط حسابي (3.75) وانحراف معياري (0.83)، بينما جاءت الفقرتين (10، 12) في المرتبة الثانية، بمتوسط حسابي (3.50) وانحراف معياري (0.50)، واللتين تتصان على" أسهم التعليم عن بعد في زيادة نشاط وحيوية المتعلمين للتعلم "و و ساعد التعليم

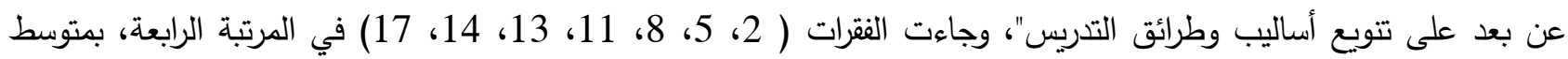
حسابي (3.25) وانحراف معياري (33.43)، بينما جاءت الفقرات ( 1، 3، 15، 15، 16، 20) في المرتبة رقم (11) بمتوسط حسابي (3.00) وانحراف معياري(31) واندان)، وجاءت الفقرات ( 4، 18، 19) في المرتبة (16) بمتوسط حسابي(2.75) وانحراف معياري (0.43)، وجاءت الفترتين ( 6، 7) في المرتبة (20) بمتوسط حسابي (0.20) وانحراف معياري ( 0.71). حيث يُظهر الجدول أن درجا الرضا عن التعليم عن بعد كانت متوسطة على المقياس الكلي، وعلى جميع الفقرات متوسطة عدا الفقرتين (6، 7) 7) كانت

درجة الرضا منخفضة. يتضح من الجدول (4) أن الدرجة الكلية لرضا أفراد عينة الدراسة من المعلمين عن التعلم عن بعد كانت متوسطة، حيث بلغ المتوسط الحسابي لهذه الدرجة( 3.08) وفق مقياس ليكرت الخماسي.

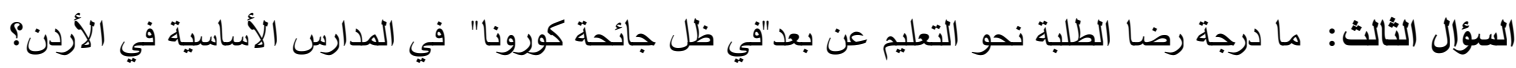
للإجابة عن هذا السؤال تم استخراج المتوسط الحسابي والانحراف المعياري والوزن النسبي لكل فقرة، وكانت النتائج كما في

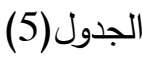
جدول(5):المتوسط الحسابي والانحراف المعياري ودرجة الرضا والوزن النسبي لأداء الطلبة على مقياس الرضا عن التعليم عن بُعد البعد

\begin{tabular}{|c|c|c|c|c|c|}
\hline 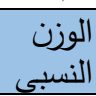 & الرضى & 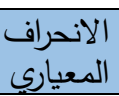 & المتوسط & الفقرة & 5 \\
\hline 11 & متوسطة & 0.71 & 3.00 & التعليم عن بعد يتتاسب مع قدراتي العلمية. & 1 \\
\hline 5 & متوسطة & 0.43 & 3.25 & أسهر التعليم عن بعد في تتمية قدراتى الذاتية. & 2 \\
\hline 11 & متوسطة & 0.71 & 3.00 & ساعدنى التعليم عن بعد فى تعزيز فهمى للمادة الدراسية. & 3 \\
\hline 16 & متوسطة & 0.43 & 2.75 & وظف المعلمون العروض التقديمية (Power point) في التعليم عن بعد. & 4 \\
\hline 5 & متوسطة & 0.43 & 3.25 & أكسبنى التعليم عن بعد مهارات جديدة لم تكن لدي من قبل. & 5 \\
\hline 20 & منخفضـة & 0.70 & 2.00 & وظف المعلمون البربد الإليكترونى (e-mail) لاستّلام الواجبات وتسليمها لنا. & 6 \\
\hline 20 & منخفضة & 0.70 & 2.00 & وظف المعلمون برامج إدارة التعلم لأغراض التعليم عن بعد... & 7 \\
\hline 5 & متوسطة & 0.43 & 3.25 & التعليم عن بعد جعلني أكثر حرصًا في التعبيرعن رأيى. & 8 \\
\hline 1 & 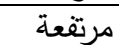 & 0.83 & 3.75 & التعليخ عن بعد زاد من مشكلة الدروس الخصوصية. & 9 \\
\hline 2 & متوسطة & 0.50 & 3.50 & سن حفظّ التعلئماتِ عن بعد على تحسين قدرتي على التفكير وحل المشكلات بدلا & 10 \\
\hline 5 & متوسطة & 0.43 & 3.25 & كان المعلم من خلال التعلير عن بعد مهتمًا بالرد على المناقشات والاستفسارات & 11 \\
\hline
\end{tabular}




\begin{tabular}{|c|c|c|c|c|c|}
\hline & & & & التي أطرحها له عن المادة العلمية. & \\
\hline 2 & متوسطة & 0.50 & 3.50 & كان المعلم متحمسًا لما يقوم بتعليمه باستخذام التعليم عن بعد. & 12 \\
\hline 5 & متوسطة & 0.43 & 3.25 & كان المعلم ملتزمًا بتنفيذ المقرر من خلال التعليم عن بعد. & 13 \\
\hline 5 & متوسطة & 0.43 & 3.25 & زادت حصيلتى العلمية من خلال استخدام التعليم عن بعد. & 14 \\
\hline 11 & متوسطة & 0.71 & 3.00 & وجن بعد. تثجيعًا من المعلمين لطرح الأسئلة وتطوير أفكاري من خلال التعليم & 15 \\
\hline 11 & متوسطة & 0.71 & 3.00 & كعد. تصحيح الواجبات والاختبارات عادلاً من المعلمين باستخدام التعليم عن & 16 \\
\hline 5 & متوسطة & 0.43 & 3.25 & التعليم عن بعد مجها ومتعب بالنسبة لى كطالب. & 17 \\
\hline 16 & متوسطة & 0.43 & 2.75 & زاد التعليم عن بعد من دافعيتى للتعلم. & 18 \\
\hline 16 & متوسطة & 0.43 & 2.75 & وجدت أن التعليم عن بعد يعطى نتائج أفضل بالنسبة لى من التعليم التقليدي. & 19 \\
\hline 11 & متوسطة & 0.71 & 3.00 & أشعر بالرضا التام عن التعليم عن بعد فى جميع المقررات الدراسية. & 20 \\
\hline & متوسطة & 0.07 & 3.03 & المقياس ككل & \\
\hline
\end{tabular}

يبين الجدول (5) أن المتوسطات الحسابية تراوحت ما بين (2 - 3.75)، حيث جاءت الفقرة رقم (9) والتي تنص على" التعليم عن بعد زاد من مشكلة الدروس الخصوصية" في المرتبة الأولى بمتوسط حسابي (3.75) وانحراف معياري( 0.83)، وجاءت الفقرتين (10، 12) في المرتبة الثانية، واللتين تتصان على " ساعدني التعليم عن بعد على تحسين قدرتي على التنكير وحل المشكلات بدلاً من حفظ المعلومات" و" كان المعلم متحمسًا لما يقوم بتعليمه باستخدام التعليم عن بعد"، بمتوسط حسابي (3.50) وانحراف معياري (0.50)، بينما جاءت الفقرات ( 2، 5، 11،8، 13، 14، 17) في المرتبة الخامسة، بمتوسط حسابي (3.25) وانحراف معياري( 0.43)،وجاءت الفقرات (1، 3، 15، 16، 20) في المرتبة (11) بمتوسط حسابي (0.3) وانحراف معياري (0.71)، وجاءت الفقرات ( 4، 18، 19) في (16) بمتوسط حسابي(2.75) وانحراف معياري (0.43)، بينما جاءت الفقرتين (6، 7) في المرتبة (20) والأخيرة بمتوسط حسابي (0.20) وانحراف معياري ( 0.70). ويلاحظ من الجدول أن درجة الرضا عن التعليم عن بعد على المقياس الكلي كانت متوسطة بمتوسط حسابي(3.03) و انحراف معياري ( 1 (0.07).

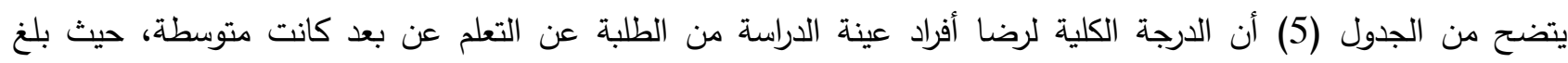
المتوسط الحسابي لهذه الدرجة( 3.03) وفق مقياس ليكرت الخماسي. السؤال الرابع: ما درجة رضا أولياء الأمور نحو التعليم عن بعد في المدارس الأساسية العليا في الأردن "في ظل جائحة كورونا"

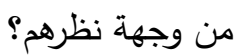
للإجابة عن هذا السؤال تم استخراج المتوسط الحسابي والانحراف المعياري ودرجة الرضا والوزن النسبي لكل فقرة، وكانت النتائج

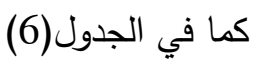
جدول(6):المتوسط الحسابي والانحراف المعياري ودرجة الرضا والوزن النسبي لأداء أولياء الأمور على مقياس الرضا عن التعليم

\begin{tabular}{|c|c|c|c|c|c|}
\hline النسبي الوزن & الرضا & الالانحراف & الحستوسي & الفقرة & 5 \\
\hline 12 & منخفضة & 0.47 & 2.33 & ساهم التعليم عن بعد في التواصل الفعال مع المعلمين. & 1 \\
\hline 15 & منخفضة & 0.81 & 2.00 & ساهم التعليم عن بعد في التواصل الفعال مع إدارة الددرسة. & 2 \\
\hline 5 & متوسطة & 0.47 & 2.66 & ساهم التعليم عن بعد في تتظيم موارد الأسرة. & 3 \\
\hline 15 & منخفضة & 0.81 & 2.00 & ساهم التعليم عن بعد فى إدارة وقت الأسرة بشكل فعًال. & 4 \\
\hline 5 & متوسطة & 0.47 & 2.66 & التعليم عن بعد يعتبر مضيعة للوقت. & 5 \\
\hline 2 & متوسطة & 0.81 & 3.00 & التعليخ عن بعد مجهذ ومكلف لنا كأولياء أمور . & 6 \\
\hline 5 & متوسطة & 0.47 & 2.66 & أشعر بالرضا عن تحصيل إبنى العلمى عن طريق التعليم عن بعد. & 7 \\
\hline 1 & متوسطة & 0.47 & 3.33 & ساهم التعليم عن بعد في تحمل المسؤولية لدينا كأولياء أمور . & 8 \\
\hline 12 & متوسطة & 0.47 & 2.33 & التعليم عن بعد يناسب قدرات أبنائي في التعلم. & 9 \\
\hline 2 & متوسطة & 0.82 & 3.00 & كان التعليم عن بعد منتظمًا من قبل المعلمين. & 10 \\
\hline 5 & متوسطة & 0.47 & 2.66 & كان المعلم يرد على اقتراحاتتا كأولياء أمور عن التعليم عن بعد. & 11 \\
\hline 2 & متوسطة & 0.81 & 3.00 & كانت المدرسة تتابع جميع الثكاوى وتعمل على حلها. & 12 \\
\hline 5 & متوسطة & 0.47 & 2.66 & التعليم عن بعد لا يناسب جميع مراحل التعليم الأساسى & 13 \\
\hline
\end{tabular}

273 IUG Journal of Educational and Psychology Sciences (Islamic University of Gaza) / CC BY 4.0 


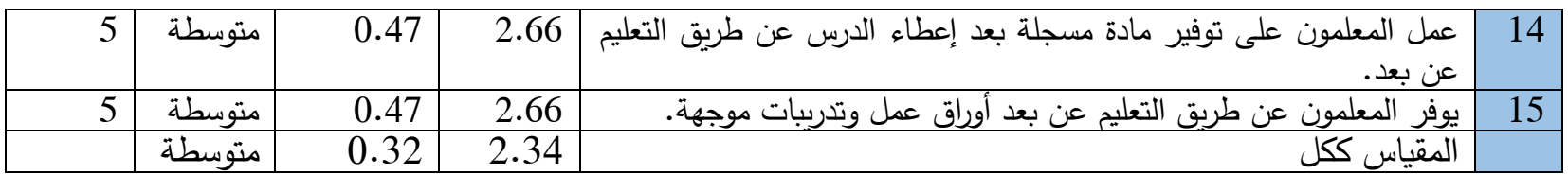

يبين الجدول (6) أن المتوسطات الحسابية تراوحت ما بين (2 - 3.33)، حيث جاءت الفقرة رقم (8) والتي تتص على " ساهم

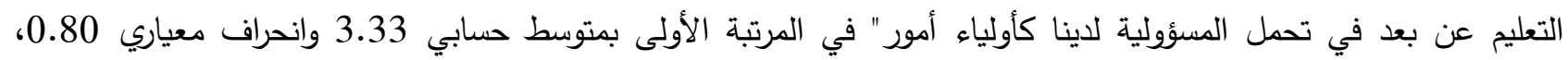

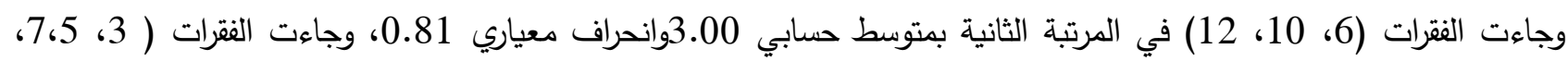

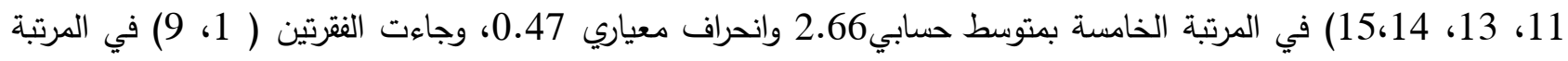
(12) بمتوسط حسابي 2.66 وانحراف معياري 0.47، وجاءت الفقرتين (2، 4) في المرتبة الأخيرة بمتوسط حسابي 2.33 وانحراف معياري 0.47. يتضح من الجدول (6) أن الدرجة الكلية لرضا أفراد عينة الدراسة من أولياء أمور الطلبة عن التعلم عن بعد كانت متوسطة، حيث بلغ المتوسط الحسابي لهذه الدرجة( 2.43) وفق مقياس ليكرت الخماسي. مناقشة النتائُج: تمت مناقشة النتائج في ضوء تسلسل أسئلة الدراسة كما يلي: كثفت النتائج أن المتوسط الحسابي لدرجة الرضا عن التعليم عن بعد لدى مديري المدارس الأساسية العليا في الأردن في ظل فل فئل جائحة " كورونا" من وجهة نظرهم بلغ (3.43) بانحراف معياري( 0.66) بدرجة متوسطة، حيث كان متوسط الرضا عن التعليم عن بعد على جميع الفقرات متوسطًا، عدا الفقرتين (3، 4) كان المتوسط منخفضًا واللتان تتعلقان بالتقييم وتصميم الاختبارات الإلكترونية، والفترتين ( 1، 20) كان المتوسط مرتفعًا واللتين تتعلقان بتعليمات التطبيق والتحفيز . وتعزى هذه النتائج إلى التحول المفاجئ من التعليم الوجاهي إلى التعليم عن بعد، حيث يرى الباحث أنه لــ يكن لاى مديري

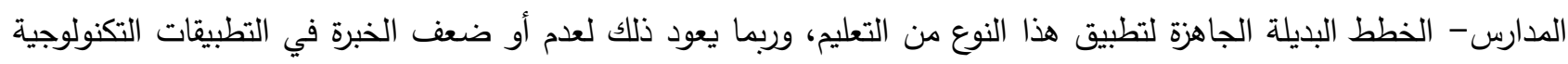

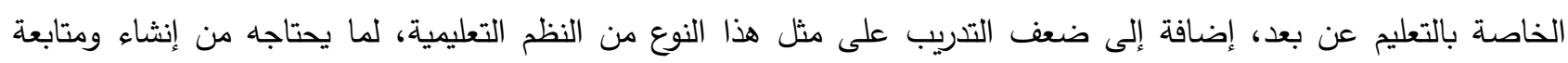
لمنصات التعلم الإلكتروني، والاحتياج لعدد كبير من الساعات والمتابعة مع المعلمين والطلبة، وكذلك التواصل مع أولياء الأمور ، وكذلك عدم التخطيط من قبل مديري المدارس لقيادة مثل هذا النوع من نظم التعلم والتعليم في ظل الأزمات والجين والجوائح. وتتقق نتيجة هذا السؤال مع نتائج دراسة الثديفات (2020م) والتي أجريت على مديري المدارس في قصبة المفرق/الأردن،

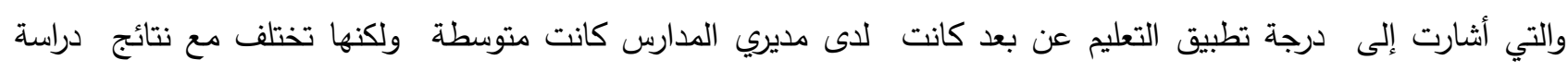
جورجي باسيليا وديفيد كفافدوزي (Giorgi Basilla, David Kavavodzw,2019 والتي أظهرت إلى أن النيقي الانتقال من التعليم التقليدي إلى التعليم عبر الإنترنت كان ناجدًا. وكثفت النتائج أن المتوسط الحسابي لدرجة الرضا عن التعليم عن بعد من وجهة نظر المعلمين في المدارس الأساسية العليا

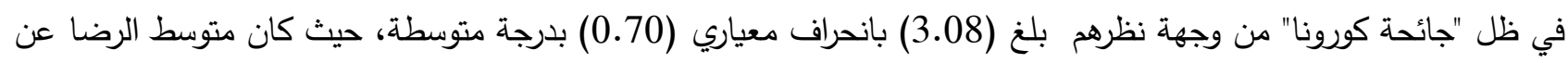

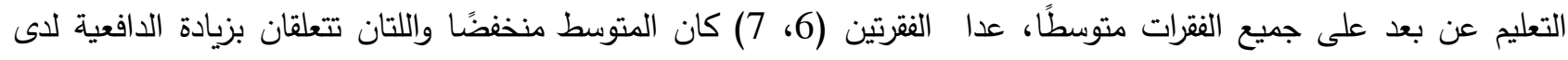
المتعلمين وتقدير المعلم لأهمية توظيف التكنولوجيا في التعليم، وجاءت درجة الرضا مرتفعة عن الفقرة (9) والتي تتعلق بالمنصات التعليمية التي وفرتها وزارة التربية والتعليم في تحفيز المعلمين على توظيف التوفيل التكنولوجيا في التعليم.

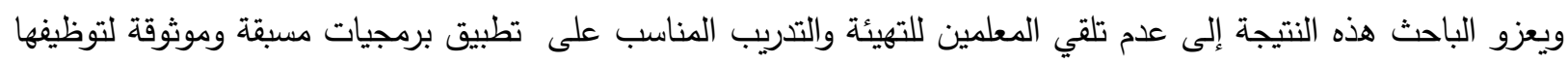
في التعليم عن بعد، الأمر الذي جعل المعلمين يتواصلون مع الطلبة عبر وسائط التواصل الاجتماعي ( صدر قرار من وزارة

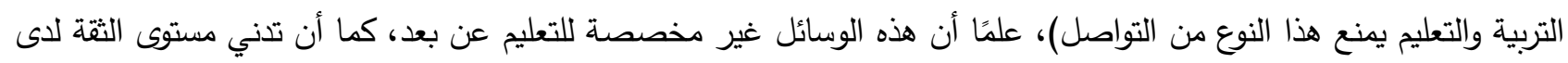

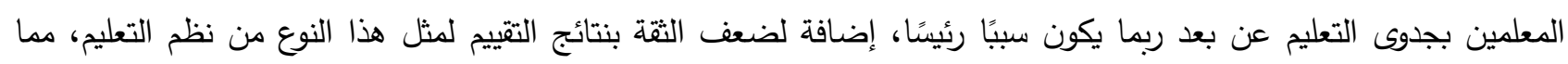


جعلهم لا يأخذون الموضوع بمحمل الجد. إضافة لقرارات وزارة التربية والتعليم التي جاءت سريعة جداً، دون تهيئة وإعداد مسبق للتعليم عن بعد في ظل الأزمات وخاصة جائحة" كورونا" ربما ساهم في درجة الرضا المتوسطة عن هذا النوع من نظم التعليم.

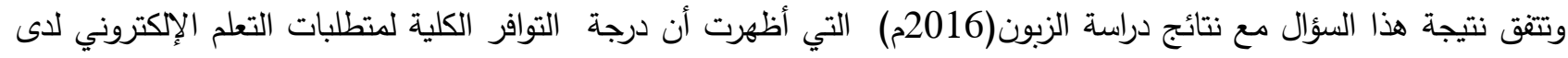
معلمي التربية الإسلامية كانت متوسطة، وتختلف عن نتائج دراسة حمادنة والثواهين (2019م) والتي أجريت على المعلمين والتي تثير إلى درجة مرتفعة من الرضا.

وكثفت النتائج أن المتوسط الحسابي لدرجة الرضا عن التعليم عن بعد للى الطلبة في ظل "جائحة " كورونا" من وجهة نظرهم بلغ (3.03) بانحراف معياري (0.07) بدرجة متوسطة، حيث كان متوسط الرضا عن التعليم عن بعد على جميع الفقرات متوسطًا،

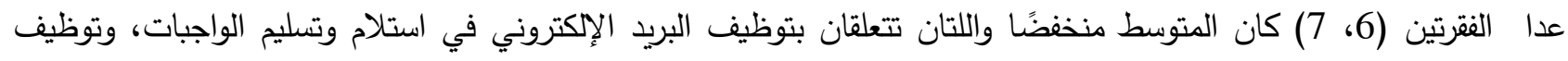
برامج إدارة التعليم عن بعد لأغراض التعليم عن بعد ، وجاءت الدرجة مرتفعة عن الفقرة (9) والتي تتعلق بزيادة الاعتماد على لـ لإنى الدروس الخصوصية بسبب تطبيق التعليم عن بعد. يعزو الباحث هذه النتيجة إلى أن تجربة التعليم عن بعد على الطلبة في الأردن كما هي في الدول العربية الأخرى تجربة

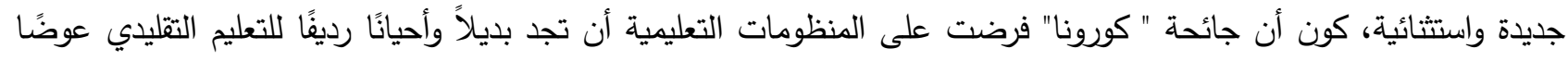

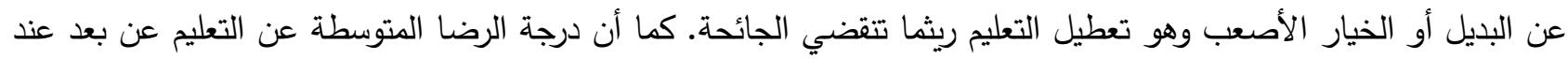

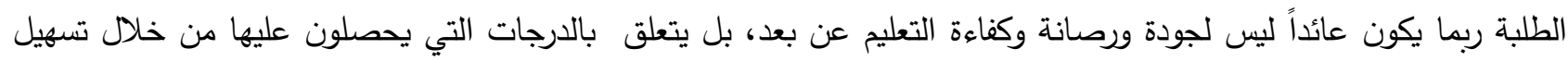

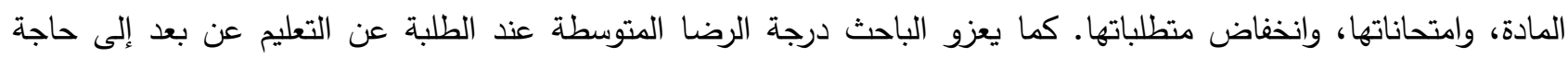
تطبيق هذا النوع من التعليم إلى بيئة تكنولوجية، وإلى ثقافة تقوم على الثقة والمصداقية والمسؤولية (وهذه تعتبر مهارات حياتية

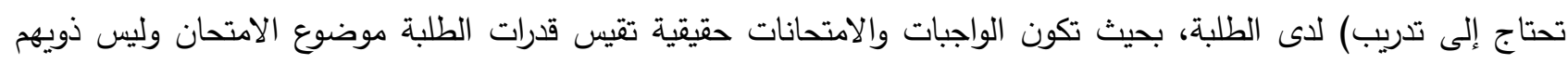
وأصدقائهم.

وتختلف وتتقق هذه النتيجة مع نتائج دراسات العشيري (2016م) والثريف(2016م)، والبيطار (2016م)، وعوض وحلس

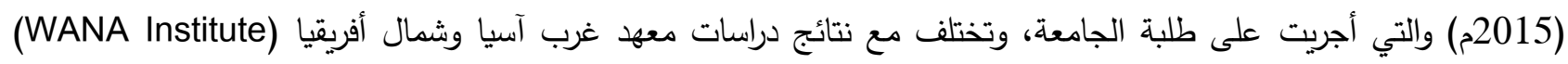

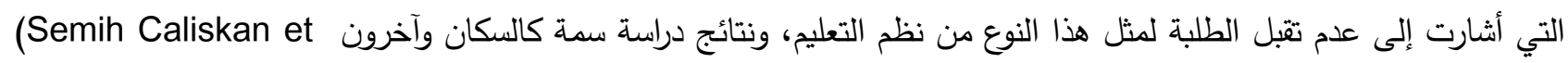
(al.,2017 والتي أشارت إلى أن درجة الرضا عن التعلم عن بعد كانت جيدة، ودراسة المقدادي ( 2020م) التي أظهرت التأثير الإيجابي للتعلم عن بعد للى الطلبة. وكثفت النتائج أن المتوسط الحسابي لدرجة الرضا عن التعليم عن بعد في ظل جائحة " كورونا" من وجهة نظر أولياء الأمور

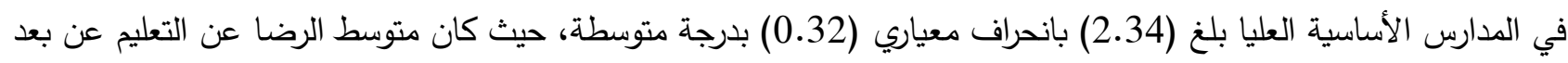
على جميع الفقرات متوسطًا، عدا الفقرتين (1، 2، 4) كان المتوسط منخفضًا والتي تتعلق بالتواصل مع المعلمين وإدارة المدرسة

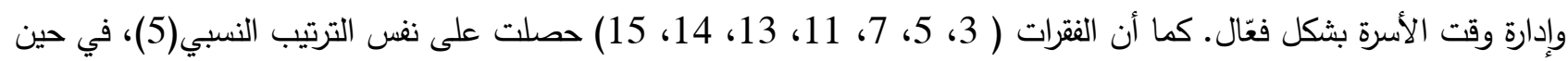

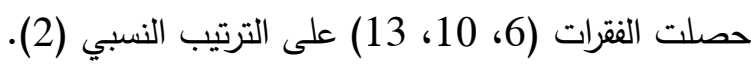
يلاحظ من النتائج الخاصة بهذا السؤال أن درجة رضا أولياء الأمور عن التعلم عن بعد هي الأقل من بين درجات رضا الفئات الفئات الأخرى ، وربما يعود السبب إلى أن بعض مهام التعلم عن بعد قد تتجاوز قدرات الطلاب وأولياء أمورهم، وقد تسبب مشاكل صحية الطية

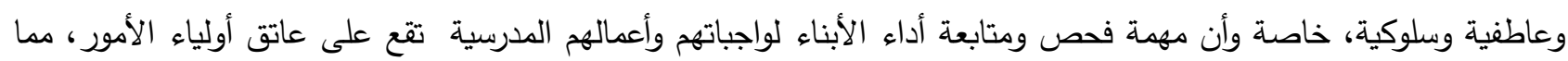
قد يؤدي إلى زيادة الضغط عليهم. كما ويعزو الباحث هذه النتيجة إلى مجموعة من الأسباب من بينها: محدودية الإمكانيات لدى أولياء الأمور لتوفير أجهزة ذكية

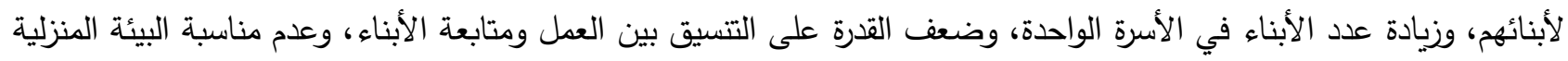


للتعليم عن بعد، وصعوبة الوصول لمنصات التعليم لعدم تدبهم على ذلك، كما يعزو الباحث الدرجة المتوسطة لرضا أولياء الأمور

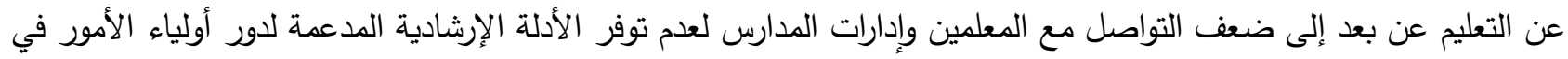
التعليم عن بعد. وتتفق نتيجة الدراسة على هذا السؤال مع نتائج دراسة ديالا وأخرون (Diala et al.,2021) في أن درجة رضا أولياء الأمور

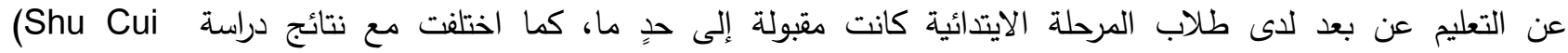
etal.,2021)

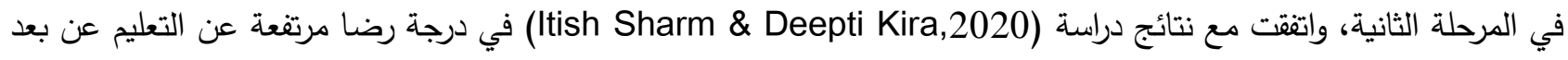
لاى طلبة المرحلة الثانوية، ولكنها اختلفت مع درجة رضا أولياء أمور المرحلة الابتدائية التي كانت منخفضة.

1- استخدام أساليب تعليم قادرة على جلب انتباه الطلبة، وزيادة تقاعلهم، وإضفاء روح المتعة لمقررات التعليم المتوفرة عبر الوسائط التكنولوجية المختلفة.

2- أن يكون التعليم عن بعد جزء من العملية التربوية، أي أن يكون هناك نوع من المزامنة والتتسيق ( بين وزارة التربية والتعليم والمنصات التعليمية ذات العلاقة). 3- تقعيل عملية التواصل بين أطراف العملية التعليمية لضمان اتصال تفاعلي بأدوات حديثة مطورة، تسمح للطالب بالمساهمة عبر المشاركة والاقتراح والتفاعل، مما يحفز مهارات الطلبة في التفكير الناقد، وحل المشكلات، والتحليل.

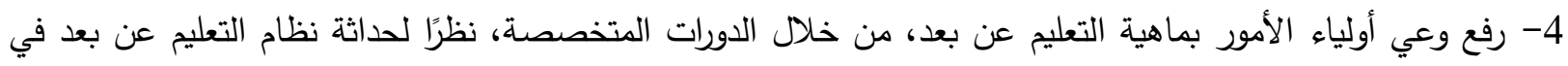
الأردن.

5- إضافة خاصية الوسائط المتعدة كالفيديوهات التعليمية إلى مقررات التعليم الموجودة عبر نظام التعليم عن بعد. 1- إجراء دراسات عن علاقة التعليم عن بعد بالتعلم المنظم ذاتيًا، والدافعية الداخلية، والكفاءة الذاتية الأكاديمية، والتوجهات الهدفية.

2- إجراء دراسات عن الصعوبات والتحديات التي تواجه مديري المدارس والمعلمين في تطبيق التعليم عن بعد بشكل جيد.

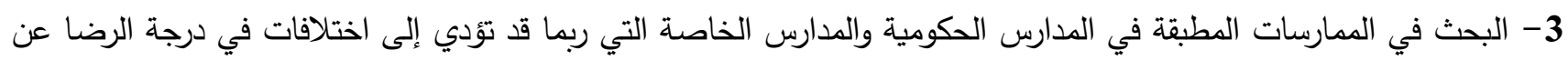

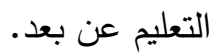

4- إجراء دراسات حول العوامل التي تحدد رضا أولياء الأمور عن التعلم عن بعد مثل الاستعداد للدروس عن بعد، والتوقيت الأسبوعي، ومحتوى المناهج الدراسية، والمخاطر الصحية، ومدى صلاحية مثل هذا النوع من نظم التعلم. 


\section{المصادر والمراجع}

أولاً: المراجع العربية:

حمادنة، مؤنس والثواهين، سوزان. (2019م). اتجاهات معلمي الرياضيات نحو التعليم الإليكتروني في مديرية تربية البادية الثمالية الشرقية. مجلة الجامعة الإسلامية للدراسات التربوية والنفسية،27(4).427-471.

أبوشخيدم،حر وآخرون .(2020م).فاعلية التعليم الإكتروني في ظل انتشار فيروس كورونا من وجهة نظر الددرسين في جامعة فلسطين التقنية (خضوري).المجلة العربية للنشر العلمي. (21)، 264 - 280

أبو ربيع، ابتسام أحمد .(2015). مستوى إدراك مديري الددارس الأساسية الخاصة لأهدية تكنولوجيا التعليم وعلاقته ببستوى توظيف المعلمين لهذه التكنولوحيا من وجهة نظر المعلمين في محافظة العاصدة عمان. رسالة ماجستير (غيرمنشورة)، جامعة الشرق الأوسط، الأردن.

الخوالدة، محد. (2015م). واقع تطبيق الإدارة الإكترونية في الددارس الثانوية الخاصة في محافظة العاصمة من وجهة نظر

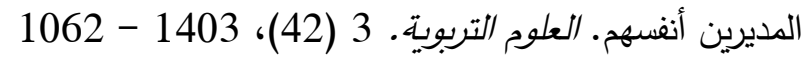

البيطار ، حمدي.(2016م). فاعلية استخدام التعليم عن بعد في تتمية التحصيل الدراسي والاتجاه نحو التعليم عن بعد في مقرر تكنولوجيا التعليم لدى طلاب الدبلوم العامة نظام العام الواحد شعبة التعليم الصناعي. دراسات عربية في التربية وعلم النغس، $.38-17.78$

الزبون، أحمد.(2016م). درجة توافر متطلبات تطبيق التعليم الإليكتروني في الأردن من وجهة نظر عينة من معلمي التربية الإسلامية في محافظتي جرش وعجلون. دراسات، العلوم التربوية،43، (2). 513-532.

الثديفات، منيرة.(2020م). واقع توظيف التعليم عن بعد بسبب مرض الكورونا في مدارس قصبة المفرق من وجهة نظر مديري

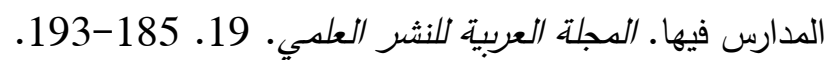

الشريف، محمد .(2016م). اتجاهات طلبة جامعة شقراء نحو التعليم الإكتروني. مجلة كلية التربية، جامعة الأزهر ، 168 (3). 891 $.931-$

الشياب، إسراء (ب.ت). " التعليم عن بعد" في الأردن في ظل أزمة كورونا . http://wanainstitute.org/en تم الاسترجاع بتاريخ 4/7/2021

العشيري، هشام. (2016م).قياس اتجاهات طلبة الجامعة العربية المفتوحة في مملكة البحرين نحو نظام التعليم المفتوح. مجلة دراسات نفسية وتربوية. (17)1-12.

العريفي، سلطان.(2020م).درجة رضا أعضاء هيئة التدريس في جامعة شقراء عن التعليم الإلكتروني في ظل جائحة كورونا النواحي التعليمة من وجهة نظرهم. مجلة علوم الإنسان والمجتمع. 10 (2)، 473 - 402 - 502

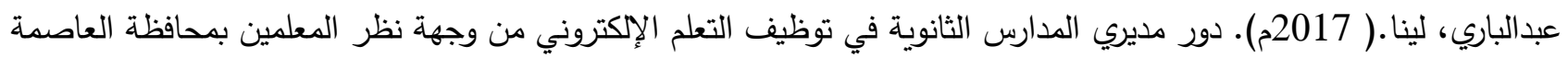
عمان. رسالة ماجستير ، جامعة الثرق الأوسط، الأردن. عوض، منيروحس، موسى.(2015) الاتجاه نحو تكنولوجيا التعلم عن بعد وعلاقته ببعض المتغيرات لدى طلبة الدراسات العليا في الجامعات الفلسطينية. مجلة جامعة الأقصى (سلسلة العلوم الإنسانية)، 19 (1) 219.

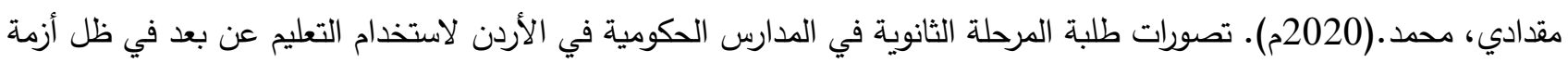

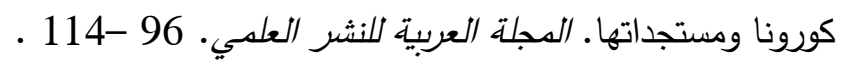

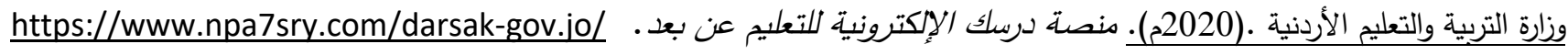

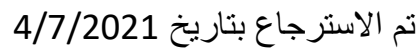
وز ارة التربية و التعليم الأردنية. قانون وزارة التربية والتعليم الأردنية وتعدلاته (1994). 


$$
\text { وزارة التعليم العالي والبحث العلمي الأردنية. 4/7/2021 }
$$

Abed-Albari, Lina.(2017). The Role of Secondary School Principals in Applying ELearning from Teachers' Point of View in Amman Governorate.(Master thesies). Middle East University, Jordan.(in Arabic).

Albitar, H. (2016). The effectiveness of using of distance learning in developing academic achievement and attitude toward distance learning in instructional technology course of first -year system general Diploma educational students. (in Arabic).Arab studies of education and psychology. (78),17-38

Abu rabee, Ebtisam.(2015). The level of private basic school principals perception of educational technology importance and its relation to teachers application of technology from teachers' point of view in the capital Amman. .(in Arabic) . Master thesies). Middle East University, Jordan.

Abu shkadim,Saher et al., (2020). The effectiveness of e-learning in light of the spread of the Corona virus from the point of view of teachers at Palestine Technical University (Kadoorie). .(in Arabic).Arab Journal for Scientific Publishing.(21), 264-389.

Alkawaldeh, Muhammed .(2015). The actual application of the electronic administration in secondary private schools in the Governorate of the Capital of Jordan from the perspective of the principals. (in Arabic).Educational science, 3(42), $1043-1062$

Al-shdefat, M.(2020). "The Reality of the Employment of the Distance Education Due to Corona" (Disease in the Schools of kasabah AL Mafraq from the Principals Perspective) (in Arabic). Arab Journal for Scientific Publishing (AJSP).(19)185-193.

Aloshairi,H.(2016). measure the students' attitudes at the Arab Open University - Kingdom of Bahrain branch.(in Arabic). Psychological and Educational Studies. (17)1-12.

Alshyab, Esra..Distance education in Jordan in light of the Corona crisis. http://wanainstitute.org/en. Retrieved 4/7/2021

Aloraifi,Sultan .(2020). The degree of satisfaction of faculty members at Shaqra University about e- learning in light of the Corona pandemic, from the educational aspects, from their point of view.(in Arabic). Journal of Human and society. 10(2),473-502

Alzbon, A.(2016). The Availability Requirements of the Application of E-learning in Jordan, from the point of View of a Sample of Teachers of Islamic Education in the Governorates of Jerash and Ajloun in Jordan.(in Arabic). Derasat.Educational Science. 43(2) 513-532.

Auad, M, Hillis M.(2015).Attitude towards distance learning technology and its related with some variables with post graduate students at Palestinian universities.(in Arabic).Al-Aqsa University Journal (Humanities Series), 19 (1)219-256

Google (2020). 'Hangouts Meet improvements for remote learning March 19, 2020'. Retrieved on 6 April 2020 from https://gsuiteupdates.googleblog.com/2020/03/hangouts-meet-edu-updates.html

Hamadneh, M, Alshwaheen S.(2019). The Attitude of Mathematics Teachers Towards E-learning in North- East Badia Directorate(in Arabic). IUG Journal of Educational and Psychology Sciences (Islamic University of Gaza).27(4)457-471.

mikdaday,Muhammed.(2020). "Perceptions of High School Students in Government Schools in Jordan to Use Distance Education in Light of the Corona Crisis and its Developments".)in Arabic). Arab Journal for Scientific Publishing,.96-114.

Ministry of Higher Education and Scientific Research (2020).How effective of distance learning. (in Arabic). http://www.mohe.gov.jo.

World Bank Blogs. Corona virus (COVID-19)(2020). Schools readiness for digital learning in the opinion of school principals.AN analysis from the international student assessment program 2018 and its implications of the response to the Corona virus Crises. .(in Arabic). https://blogs.worldbank.org

World Bank Blogs. Corona virus (COVID-19)(2020). Pandemic and preparation for digital learning in Jordan.(in Arabic). https://blogs.worldbank.org

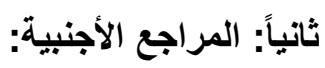

Abdulrahman E, Abdelrahim F, Fathi M, and Rafdan H.(2020). Distance education as a response to pandemics: Coronavirus and Arab culture..Technology of socity,Vol ,63, https://doi.org/10.1016/j.techsoc.2020.101317

Abu Sarah, A. (2020). Using digital technology in education in times of crisis: Coronavirus as a model. http://www.neweduc.com 
Adams Becker, S., Freeman, A., Giesinger Hall, C., Cummins, M., \& Yuhnke, B. (2016). NMC/CoSN horizon report: 2016 K-12 edition. The New Media Consortium. https://www.learntechlib.org/p/173568

Aljaser, A. M. (2019). The effectiveness of e-learning environment in developing academic achievement and the attitude to learn English among primary students. Turkish Online Journal of Distance Education-TOJDE, 20(2), 176194Alshareef.(2016). students' attitudes in Shaqra University towards e-learning(in Arabic). Journal Education College, Al-Azhar University. 168(3), 891-931.

Annelies, R., Pieter, V., Marieke, P., Ine, W., Wim, V., \& Fien, D. (2020). Learning and instruction in the hybrid virtual classroom: An investigation of students' engagement and the effect of quizzes. Computers \& Education. https://doi.org/10.1016/j.compedu.2019.103682

A.W. Tony ,B.(2005).Studies in Distance Education Series. https://www.routledge.com/Routledge-Studies-in-Distance Education/book

Basilaia, G., et al. (2020) 'Replacing the Classic Learning Form at Universities as an Immediate Response to the COVID-19 Virus Infection in Georgia', International Journal for Research in Applied Science \& Engineering Technology (IJRASET), 8(III), 101-108. https://doi.org/10.22214/ijraset.2020.3021

Cai, H., \& Chen, M. (2019). Research on the construction and development of digital education resources in an intelligent age. Modern Distance of Education, (3), 74-81

CEDEFOP: (2021).European Center for the Developmental and Vocational Training: Corona virus: Distance Learning

Increase dropout risk for Vulnerable Learners. https://www.cedefop.europa.eu/en/news-and-press/news

Cox, M. (2013). Formal to informal learning with IT: Research challenges and issues for e-learning. Journal of Computer Assisted Learning, 29(1), 85-105. https://doi.org/10.1111/j.1365-2729.2012.00483.x

Diala A.Hamaidi,YouseF, M,. Arouri, Rana K. Noufal, and Islam T. Aldrou (2021). Parents' Perceptions of their children's experiences With Distance Learning During the COVID-19 Pandemic. International Review of Research in Open and Distributed Learning.22(2). http://www.irrodl.org/index.php/irrodl/article/view/5154/5495

Hodges, C., Moore, S. Lockee, B., Trust, T., Bond, A. (2020). The Difference Between Emergency Remote Teaching and Online Learning https://er.educause.edu/articles/2020/3/the-difference-between-emergency-remote = teaching-and-online-learning. Retrieved, 27/5/2020

Hope Kentnor. (2015). Distance Education and the Evolution of Online Learning in the United States. https://digitalcommons.du.edu/cgi/viewcontent.cgi?article

Itish Shama, Deepti Kira .(2021). Study of parent's satisfaction for online classes under lockdown due to COVID-19 in India. Journal of statistics and management system.24(1) https://doi.org/10.1080/09720510.2020.1833452

Cornock M. (2020).Scaling up online learning during the Coronavirus (Covid-19) pandemic. Matt Cornock Website. 202012 March 2020. [Google ScholarGathy Li, Farah.(2020).

Khaddage, F., Müller, W., \& Flintoff, K. (2016). Advancing mobile learning in formal and informal settings via mobile app technology: Where to from here and how? Educational Technology \& Society, 19(3), 16-26.

The COVID-19 Pandemic has Challenged Education forever. https://www.polyu.edu.hk/sllo/hackathon/index.php/library.

Giorgi Basilaia \& David Kavavadze. (2020). Transition to Online Education in Schools during a SARS-CoV-2 Corona virus (COVID-19) Pandemic in Georgia. Pedagogical Research 5(4), em0060. https://doi.org/10.29333/pr/7937 Retrieved, 27/5/2020 246.

Malkawi, E., Bawaneh, A., \& Bawa'aneh, M. (2021). Campus off, education on: UAEU students' satisfaction and attitudes towards E-learning and virtual classes during COVID 19 pandemic. Contemporary Educational Technology, 13(1), ep283. https://doi.org/10.30935/cedtech/8708

Mohammed, A, Maja,C , Aishwarga.(2020). COVID-19 and digital learning preparedness in Jordan. ALBANKALDAWLI.ORG.

Müller L.M., Goldenberg G. Chartered College of Teaching; London: 2020. Education in Times of Crisis: the Potential Implications of School Closures for Teachers and Students. [Google Scholar]

Obaid Ullah et al. (2017). Students' Attitude towards Online Learning at Tertiary Level. PUTAT-Humanities and Social Sciences. 125(1-2). (Special Issue-Media Matters 63-82).

Rangiwai B. (2020). The potential impacts of COVID-19 for the master of applied indigenous knowledge (MAIK). programme in Māngere. Te Kaharoa. ;15(1):1-14. [Google Scholar]

Roumiana Peytcheva-Forsyth, Blagovesna Yovkova, and Lyubka Aleksieva. Factors Affecting Students' Attitudes towards Online Learning - The Case of Sofia University. Cite as: AIP Conference Proceedings 2048, 020025 (2018); https://doi.org/10.1063/1.5082043 Published online: 11 December 2018.

Shu Cui .(2021). Experiences and Attitudes of Elementary School Students and Their Parents Toward Online Learning in China During the COVID-19 Pandemic: Questionnaire Study. Journal of medical internet research..25(5). doi: 10.2196/24496

Semih Caliskan et al. (2017).Determining student satisfaction in distance education courses. Science., Pages 529-538 
Schuck, S., Kearney, M., \& Burden, K. (2017). Exploring mobile learning in the third space. Technology, Pedagogy and Education, 26(2), 121-137. https://doi.org/10.1080/1475939X.2016.1230555

S.K.Ingec.(2015). ). Investigation of students, Attitudes towards E-Learning in terms of different variables. A case study in a Technical and vocational high school for girls. Educational research reviews. Vol 1.,81-91

Taylor D., Grant J., Hamdy H., Grant L., Marei H..(2020). Venkatramana M. Transformation to learning from a distance. MedEdPublish. 2020;9(1):1-12. [Google Scholar]

The COVID-19 pandemic has changed education forever. https. https://marsdd.com/news/how-the-pandemic

World Bank Blogs. Corona virus (COVID-19). Pandemic and Preparation for Digital Learning in Jordan.https://blogs.worldbank.org.

World Bank Blogs Schools readiness for digital learning in the opinion of school principal Analysis from the International Students Assessment Program 2018 and its implications for the response to the Coro virus crisis.(https://blogs.worldbank.org).

Zhou, L., Wu, S., Zhou, M., \& Li, F. (2020). 'School's out, but class' on', the largest online education in the world today: Taking China's practical exploration during The COVID-19 epidemic prevention and control as an example. Best Evidence of Chinese Education, 4(2), 501-519. https://doi.org/10.15354/bece.20.ar023 